

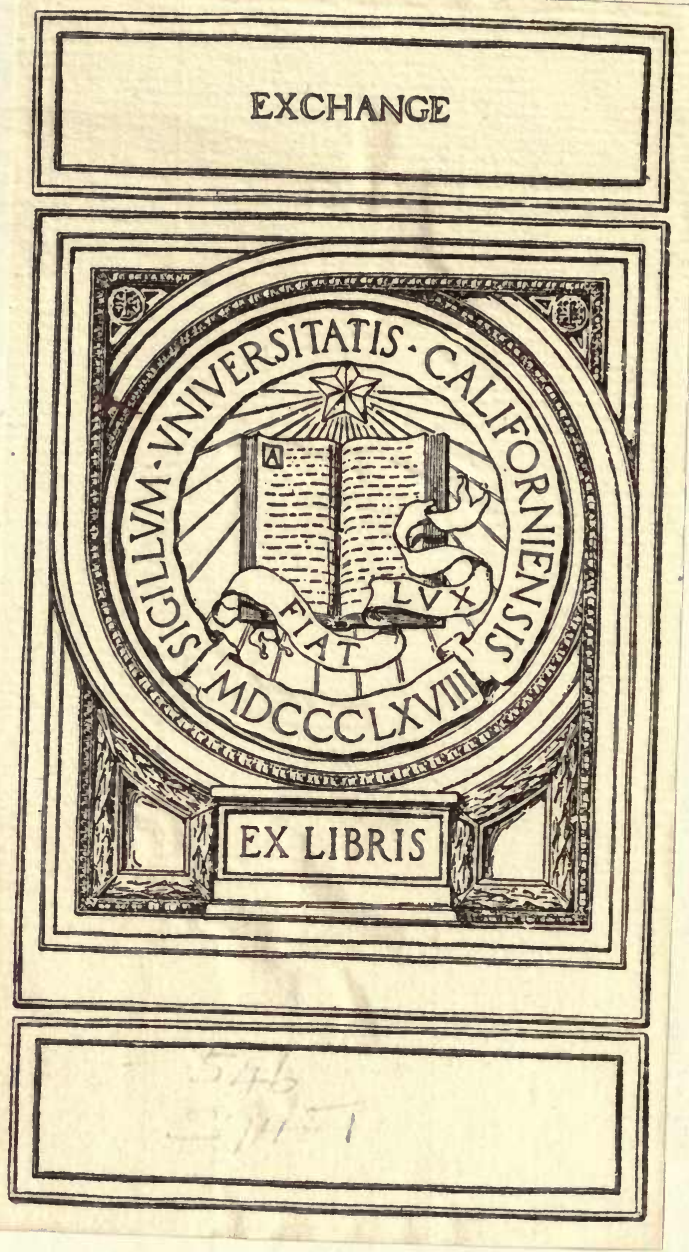







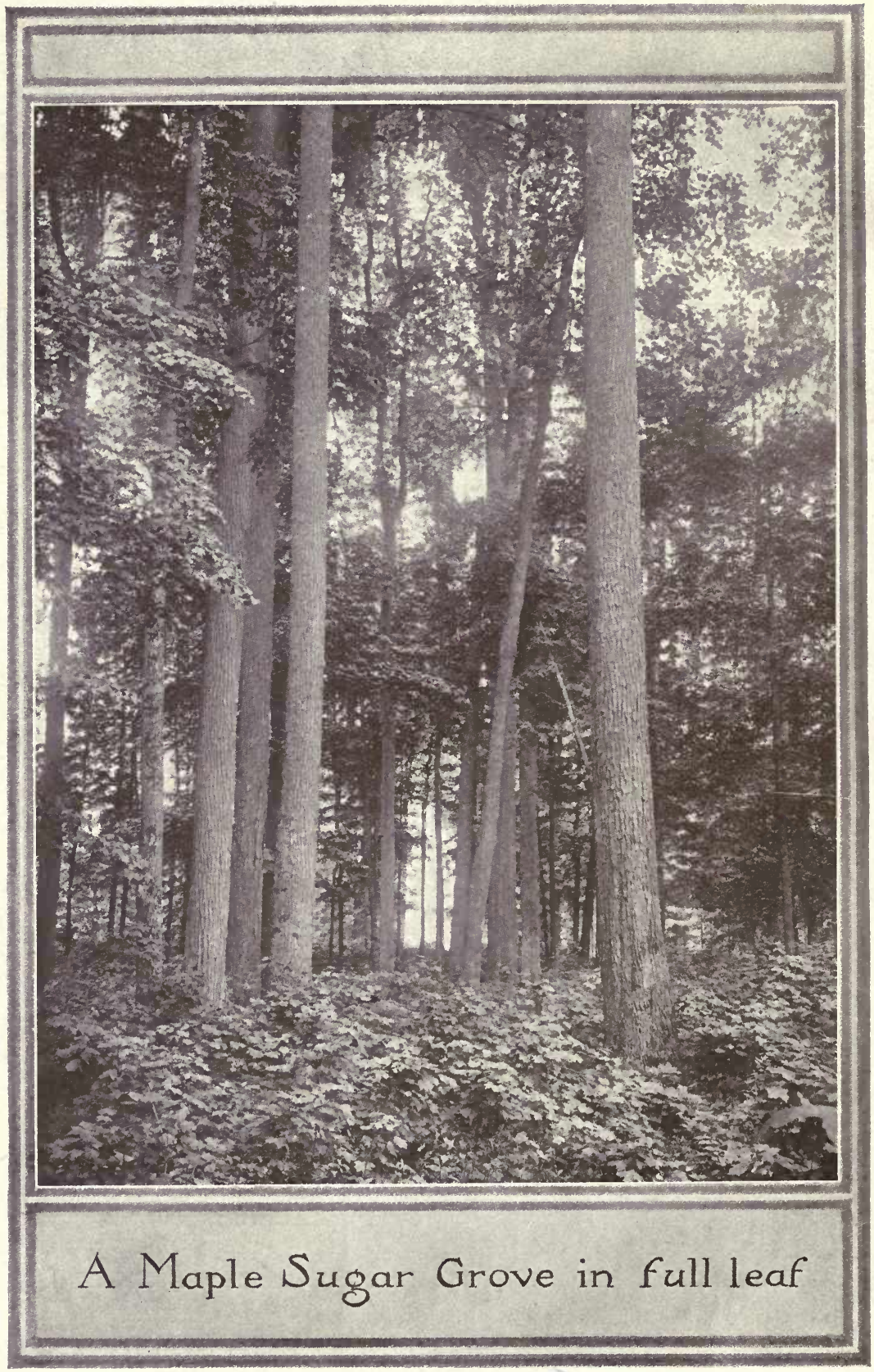





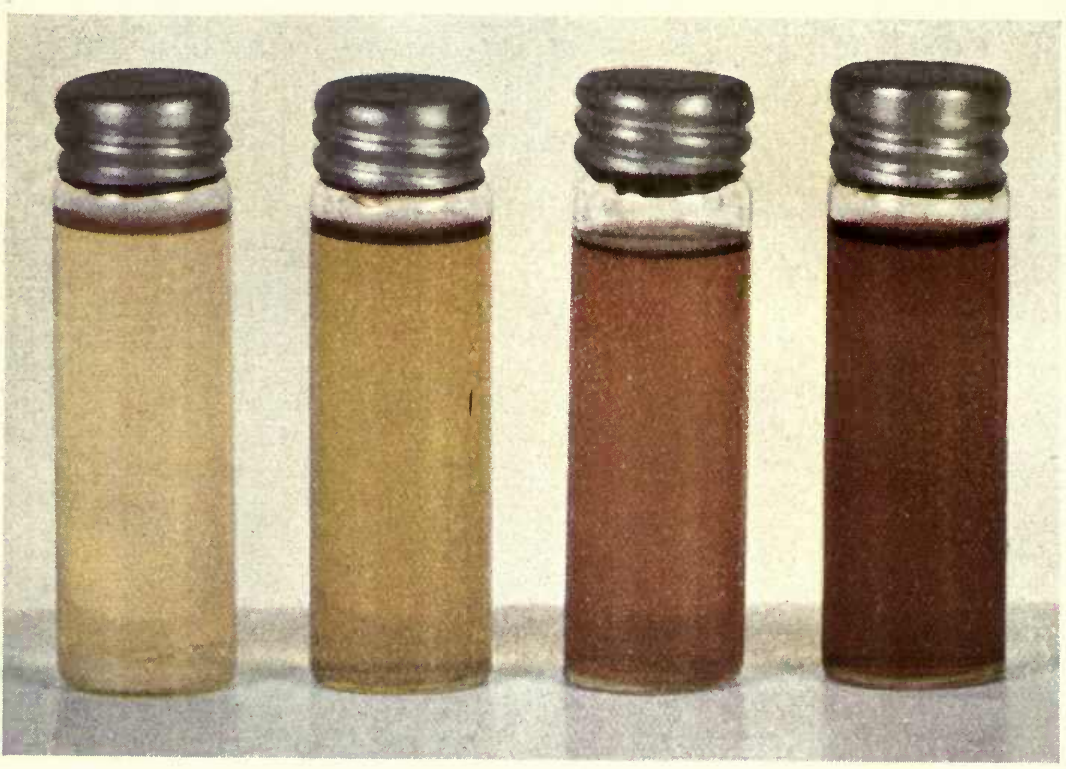

Fig. 2. MAPLE SYRUP

Grades Nos. 1, 2, 3 and 4-See page 62

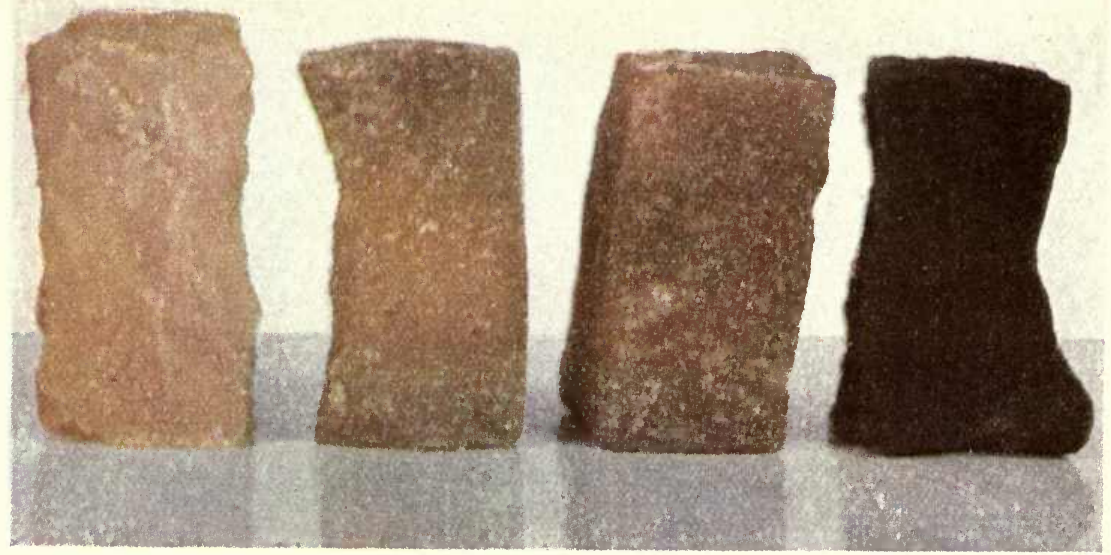

Fig. 3. Maple sugar

Grades Nos. 1, 2, 3 and 4 -See page 62 


\section{DOMINION OF CANADA \\ DEPARTMENT OF AGRICULTURE}

THE

MAPLE SUGAR INDUSTRY IN

CANADA

BULLETIN No. 2 B.

BY

J. B. SPENCER, B.S.A.

Published by Direction of the Honourable Martin Burrell, Minister of Agriculture. 


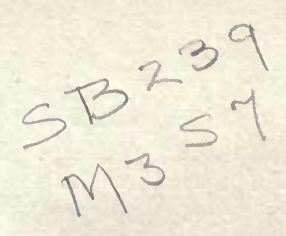

\section{ACKNOWLEDGMENTS}

In preparing this work the author used as a groundwork Bulletin No. 1B., "Maple Sugar and Syrup," published in 1907 by the Department of Agriculture: To the information taken therefrom, which has been almost entirely re-written, there has been added much new matter gathered up during the course of a tour among sugar makers at work in their groves in the Spring of 1913. Credit must also be given to publications of the Vermont Maple Sugar Makers' Association, to proceedings of the Pure Maple Sugar and Syrup Co-operative Agricultural Association of Canada and to Farmers' Bulletin No. 516 of the United States Department of Agriculture, "The Production of Maple Syrup and Sugar."

Most of the photographs reproduced were taken by the author; but for others grateful acknowledgment is due Prof. E. J. Zavitz, Forester of the Department of Lands and Forests, at Toronto, who supplied the originals of the front cover half tone and the frontispiece. Thanks is also due the Grand Trunk Railway System for the use of scenes depicting sugar making in the Algonquin Park, while Canadian manufacturers of modern equipment kindly supplied illustrations of their machines and implements.

The Author.

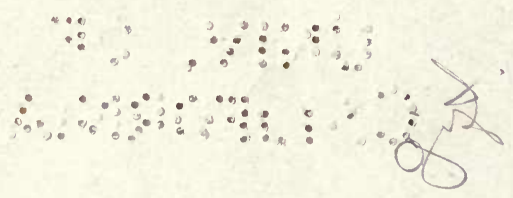




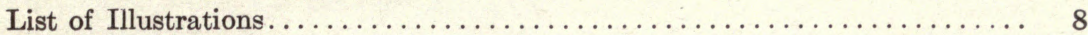

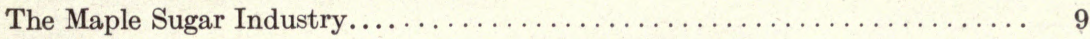

Its History and Progress.............................. 9

Its Extent and Importance........................... 12

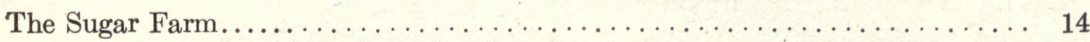

The Grove............................. 14

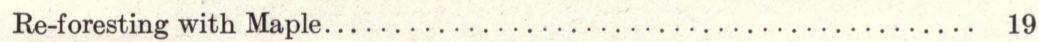

The Sugar making Plant............................... 21

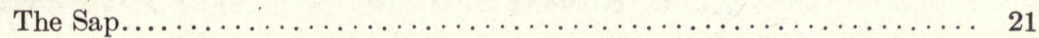

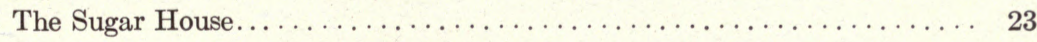

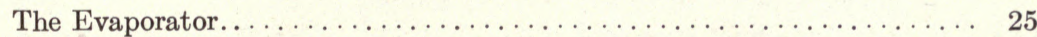

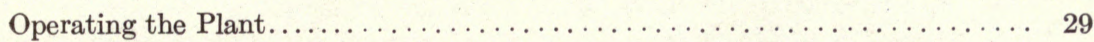

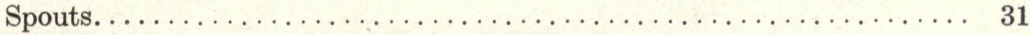

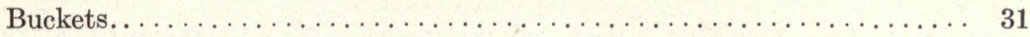

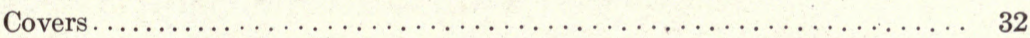

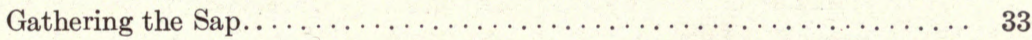

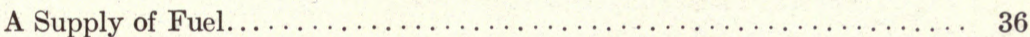

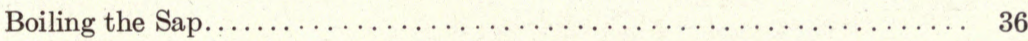

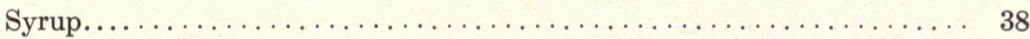

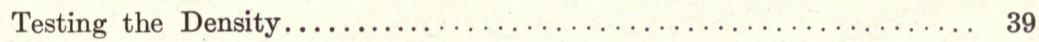

Sugar................................ 40

Cleaning the Pans............................... 42

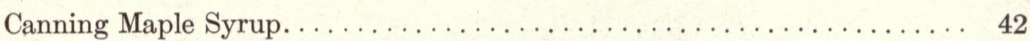

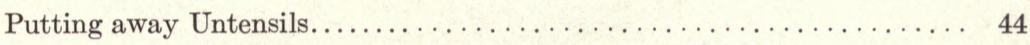

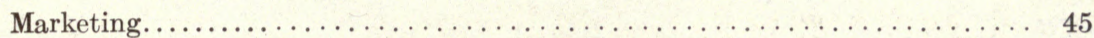

Developing a Market.......................... 46

Profits from Sugar Making......................... 47

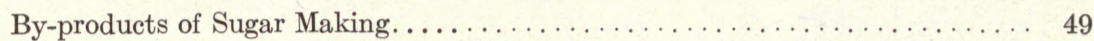

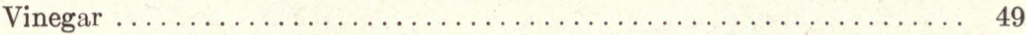

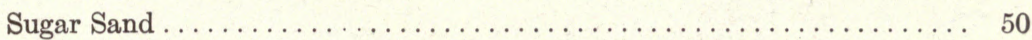

A Co-operative Maple Sugar Makers' Association................. 52

Co-operative Marketing............................... 53

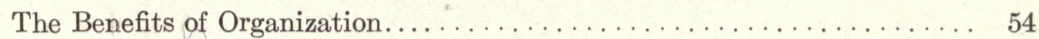

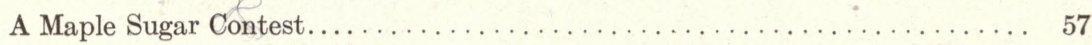

The Syrup Section............................. 57

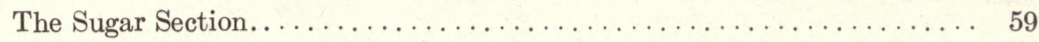

How the Prize winning Goods were made................... 59

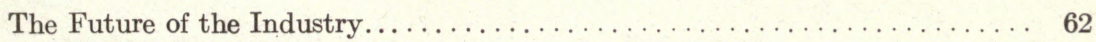

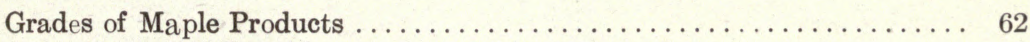

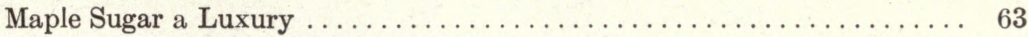


Fig. 1 A maple sugar grove in full leaf...................... 2

" 2 Maple syrup............................. 4

" 3 Maple sugar................................ 4

" 4 Scenes in the early days of sugar making................ 10

“ 5 Antiquated systems of boiling still in use in backward sections... 11

“ 6 Section of an Eastern Townships sugar bush............... 14

“ 7 Sap gatherers making the morning round............... 15

" 8 Gathering sap in the sugar bush................... 16

“ 9 Through metal pipes the sap flows from the bush to the sugar house.. 17

“ 10 A gala day in a sugar bush at Algonquin Park............... 18

" 11 A sugar house in operation in Missisquoi County, Quebec....... 21

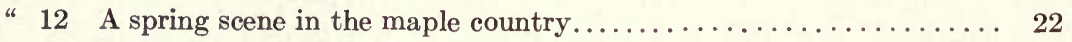

" 13 A cement concrete sugar house in Western Ontario............... 23

“ 14 A load of sap arriving at the sugar house on a sixteen hundred tree sugar orchard in Compton County, Quebec.............. 24

“ 15 A gathering tank discharging its load of sap at the sugar house... 25

" 16 Types of modern evaporators...................... 26

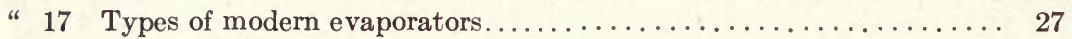

" 18 A modern gathering tank ready to be emptied at the sugar house... 28

" 19 Sap buckets receiving the run.................... 29

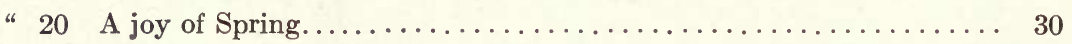

" 21 Types of $\operatorname{sap}$ spouts.............................. 31

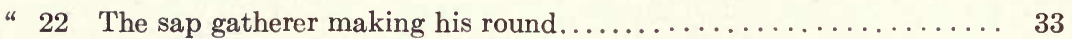

“ 23 The hand-sled and milk can used in gathering sap........... 34

“ 24 A sap gatherer and his old-fashioned outfit................ 35

" 25 View of inside of sugar house......................... 37

“ 26 Skimmer for removing scum from boiling sap............... 38

“ 27 Felt syrup strainer........................... 38

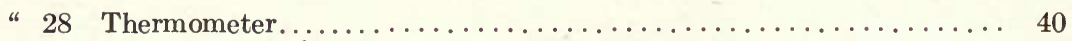

“ 29 Saccharometer................................ 40

“ 30 A case of maple syrup ready for shipment................. 43

“ 31 Label authorized by the Maple Sugar and Syrup Co-operative Agri-

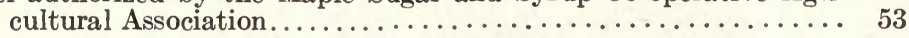

“ 32 Display of maple syrup competing in the five hundred dollar contest 58 


\section{THE MAPLE SUGAR INDUSTRY IN CANADA}

\section{Its History and Progress.}

The making of maple sugar and syrup has become but a memory in the recollection of residents in many of the older parts of Canada where even the wood lots have given up their places to cultivated fields. The industry is still, however, an important one over large areas in Quebec and to a less extent in Ontario and the provinces down by the sea.

Sugar making from the maple, which is confined entirely to this continent, had a very early beginning. Before the advent of the white man the Indian had learned to extract and concentrate the sap of the maple tree. On the approach of spring the trees were gashed, with the tomahawk, in a slanting direction and beneath the opening made was inserted a wooden chip or spout to direct the fluid drop by drop into the receptacle resting on the ground. The sap was caught in a birch bark dish and boiler in earthen kettles. The small quantity of dark, thick syrup thus made was the only sugar available to the Indians and is stated by early writers to have been highly prized.

The early settlers from the Old Land learned from the Indians the art of sugar making and indeed followed for many years their crude methods of manufacture. Even yet primitive equipment and methods are stated to be used in back sections of the country that turn out their annual crop of dark, inferior syrup and sugar.

For perhaps a century the white man followed very closely the primitive methods of the Indian save the substitution of iron or copper kettles for vessels of clay or bark. In the early days before the timber acquired much value the axe continued to be used for tapping the trees, the sap was caught in wooden troughs and conveyed in buckets on the shoulders with a sap yoke to a central point to beboiled. No sugar bush was fully equipped without snowshoes which were frequently found necessary in gathering the sap. The boiling was done in large iron kettles suspended from a pole in the open woods in a sheltered location with no protection from the sun, rain or snow or the ashes, falling leaves, moss and bits of bark that were driven about by the wind.

The maple products made by this crude method were strong in flavor, dark in color and variable in quality. 
Until about fifty years ago there was little improvement made in the methods of sugar makers; but since that time the advance has

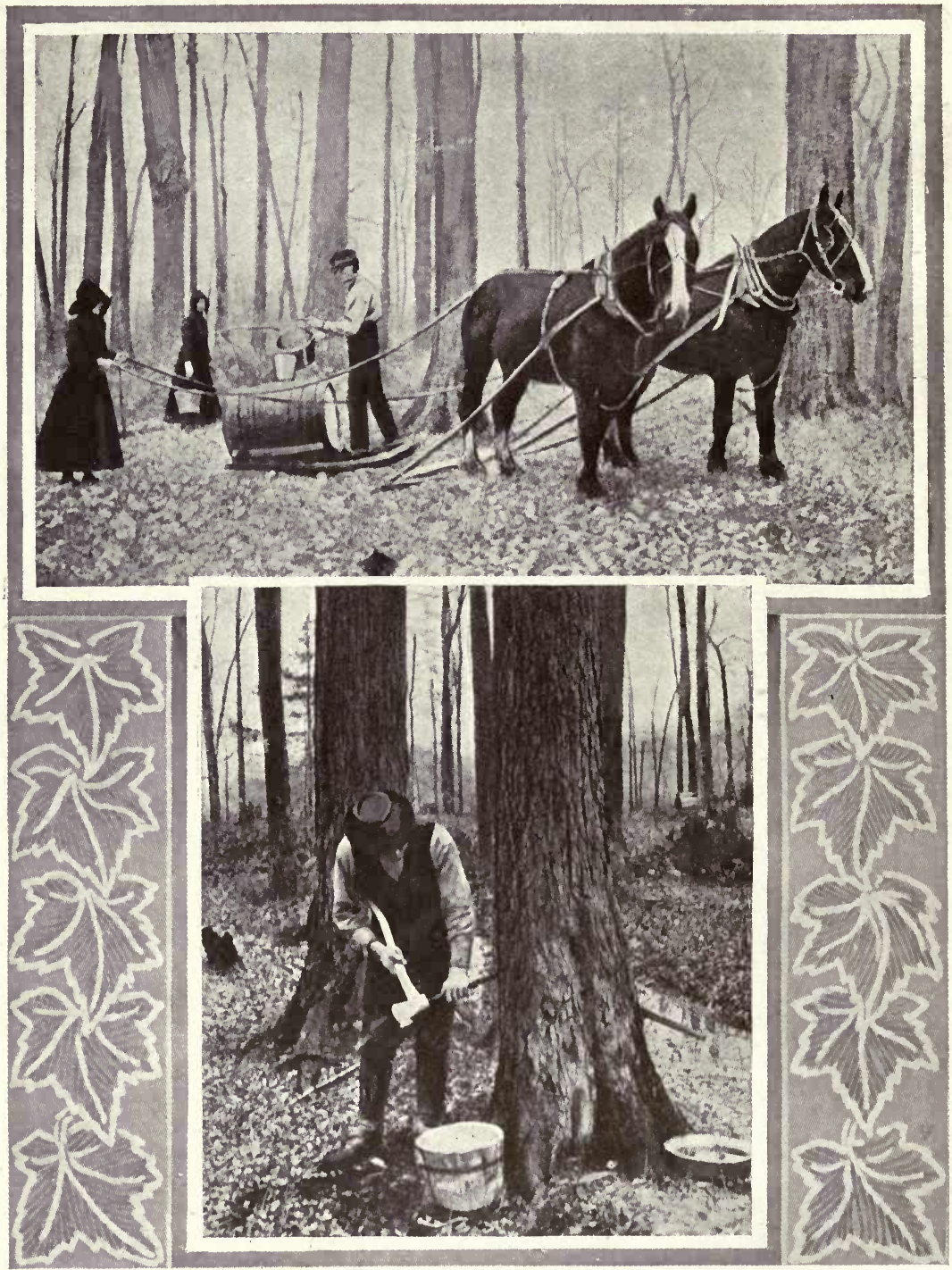

Fig. 4. SCENES IN THE EARLY DAYS OF SUGAR MAKING

The Women lent a willing hand while the season was on. In the lower picture the "old-timer" is seen tapping with the gouge and wooden spile.

kept pace with that in other branches of Agriculture until it has become a more or less highly organized commercial industry. 
An early improvement was the substitution of the auger for the axe in tapping, coopered buckets took the place of the birch bark "caso" or hewn sap trough, while the kettle gave way to the evaporating pan which has in latter years developed into the modern evaporator with corrugated bottom and separate compartments. Not alone for the conservation of the life of the tree but also for cleanliness in sugar making the wooden spout has almost disappeared in the most advanced sections, in fact the tendency now is toward the use of metal

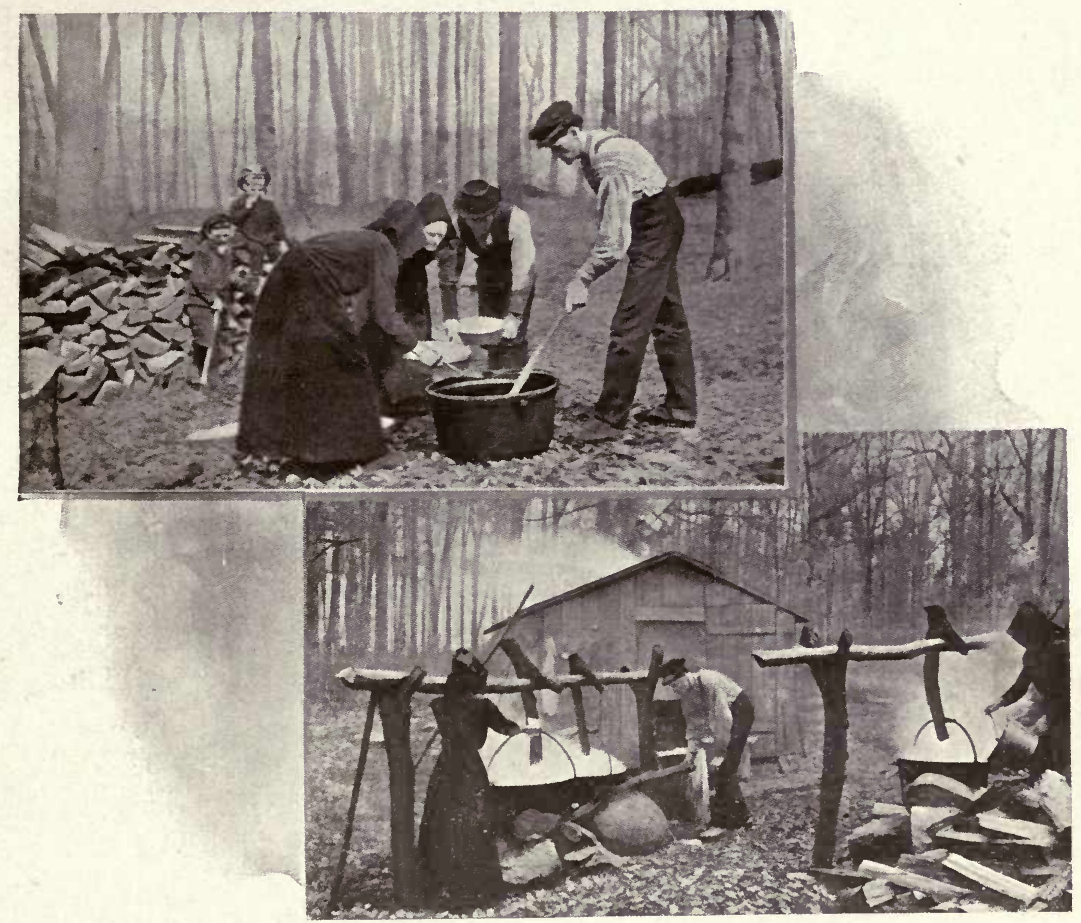

Fig. 5. ANTIQUATED SYSTEMS OF BOILING STILL IN USE IN BACKWARD SECTIONS

in every article of equipment with which the sap, syrup or sugar comes in contact. Furthermore the increasing cost of labor is being met by the ingenious inventor who has provided facilities for taking full advantage of the law oi gravitation in handling the fluid which in a well equipped plant flows of its own accord from the collecting tank to the storage vat, from thence to the evaporator and when boiled to a proper consistency into the receiving can. Indeed where the profile of the sugar orchard will permit of it pipe lines are laid 
to conduct the sap from outlying collecting centres to the camps where evaporation takes place.

With all the advances that have taken place in manipulation, sugar making has not lost its romantic side. "Sugaring Off" at the sugar camps in the woods is still looked forward to by young and old who regard the event as a social feature affording rare enjoyment. The tramp to the woods on a spring day, the aroma of the escaping steam, the partaking from a wooden paddle by means of a chip-like scoop the hot syrup just on the verge of solidifying into sugar or the tasting of the "wax" that has been allowed to harden on the clean snow all serve to inspire the reminiscent story teller and to awaken the amorous instincts of the budding youths. Such was the sugaring off of decades ago and such it is to-day where sugar orchards are operated for from two to four weeks in the spring in certain sections year after year.

\section{Its Extent and Importance.}

The importance of the maple sugar industry is scarcely realized in many parts of Canada where it has long since ceased to be carried on. From 1850 to 1890 , according to Dominion statistics, the production of maple sugar together with its equivalent in syrup increased year by year, but since that time it has steadily fallen. The average yearly production from 1851 to 1861 was about $13,500,000 \mathrm{lbs}$; from 1861 to 1871 , about $17,500,000 \mathrm{lbs}$; from 1871 to $1881,19,000,000 \mathrm{lbs}$; from 1881 to 1891 , an average of $22,500,000 \mathrm{lbs}$. was reached. During the next decade the yearly average fell to some $21,200,000 \mathrm{lbs}$. while in more recent years it has dropped to little less than 20,000,000 lbs. Even though a decrease in production is being experienced the industry still bulks large and with the more general use of modern methods and proper encouragement there is no reason why it should not return to and even surpass the high figures of the eighties.

The industry is confined in Canada to Quebec, Ontario, New Brunswick and Nova Scotia. In the Maritime Provinces the yearly output has rarely exceeded half a million pounds, Quebec turns out about 14,300,000 lbs. and Ontario 5,000,000 lbs. per year.

It is estimated that this vast industry representing an annual valuation of almost two million dollars is carried on by about 55,000 growers. While many of these operate their larger or smaller woodlots preserved upon their good farms a vastly larger number take their sap from rough and stony areas that would have comparatively little value if the trees were removed. The increasing value of maple wood 
and the comparatively low price of maple sugar and syrup, due to unfair competition from cheap adulterated products, has led in recent years to the removal of many fine sugar orchards that had produced crops of deliciousness yearly for most of a century. It is regrettable that sturdy kings of the forest have been cleared off in this way as an important yearly revenue at a season when badly needed has been cut off and one which is secured by the labor of a few weeks when it can best be spared from service on the farm. The conservation of the maple groves will, therefore, appeal to every one interested in the forest and the farm. 


\title{
THE SUGAR FARM
}

\author{
The Grove.
}

On many farms the sugar bush is simply the wood lot that has been preserved to supply fuel for the household, to afford a bit of beauty and shelter in the midst of a wind swept country and to provide an annual crop of sugar and syrup to be used as a delicacy or

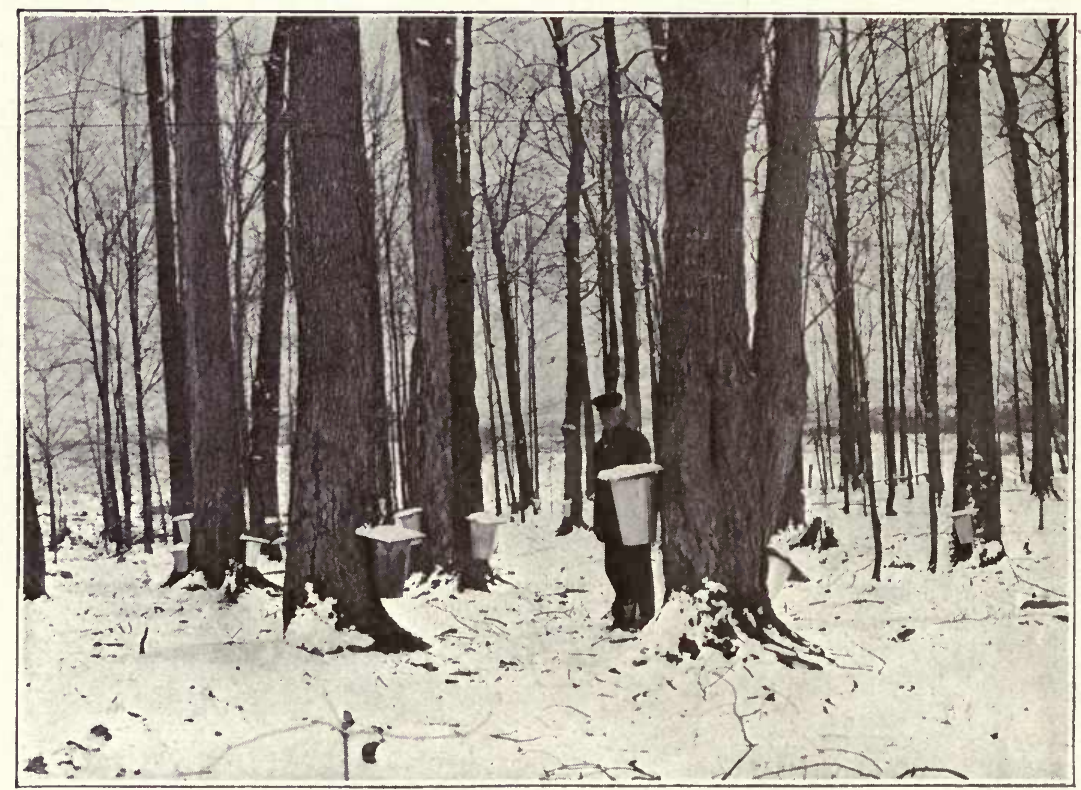

Fig. 6. SECTION OF AN EASTERN TOWNBHIPS SUGAR BUSH

Note the covered buckets and freedom from obstructions to sap gatherers

sold to regular customers at a high price. Such bushes usually contain trees of several varieties, but the maples are the last to be taken. These are usually to be found on high priced farming land where as a rule one is apt to grudge the land occupied by the trees which in many cases would scarcely be saved were it not for the annual spring harvest.

It is not from these small mixed groves that the great marketable supply is secured but rather from the more rugged areas where the plow and the harvester are not so easily operated. The groves as found in the principal sugar counties are chiefly maple trees, the other kinds having been removed for fuel or the saw. This is the con- 
dition that obtains in many of the settled counties of Eastern Ontario and of Quebec where the same groves and in many cases the same trees have been tapped by several generations. In more northerly parts of these provinces there are vast stretches of chiefly hard maple forest in a primeval state awaiting the sugar maker with his modern equipment.

In a tour among sugar makers in the Eastern Townships of Quebec it was observed that the average maple grove contains from 50 to 100 tapped trees per acre. The ideal grove would perhaps con-

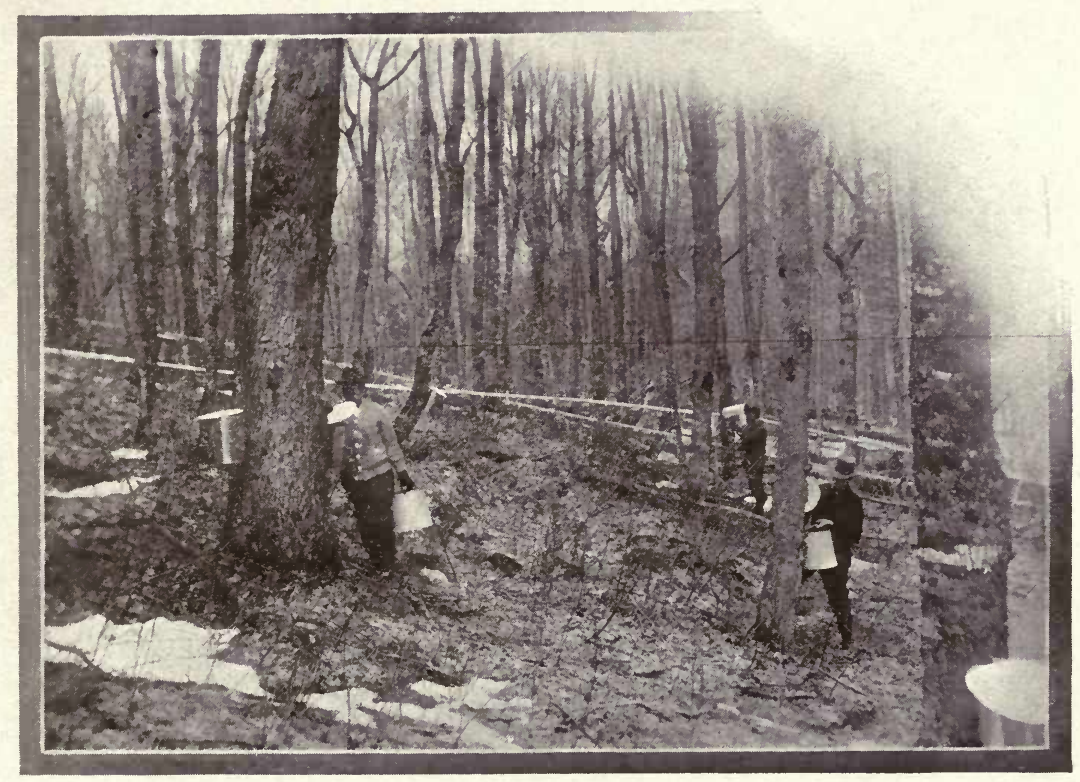

Fig. 7. SAP GATHERERS MAKING THE MORNING ROUND Sap conveyed to the sugar house by metal pipes

tain a somewhat larger number. It should be sufficient to give a maximium yield of sap per acre.

The production of sap of a sugar making quality depends on a large leaf area. From this it follows that the number of trees per acre must be consistent with the greatest crown development of each tree in the grove. A maple tree, which is a forest species, growing under this condition will produce a good length of trunk and this is necessary to a productive yield because the elaborated sugar is stored in the trunk of the tree for use during the next season; thus the trunk becomes a storage tank. The typical tree for sugar making 
is a tree with an ample root system to furnish an abundant supply of crude sap; a broad spreading top with big leaf surface to elaborate the sap and a big, long body in which the sap may be stored.

In order that an extensive leaf surface may be maintained in an active condition the soil must be protected against too great loss of moisture during the summer months. The soil must be rich, cool and moist and these conditions must be maintained from year to year. The root system of the maple is shallow, many of the fine root hairs rising nearly to the surface to absorb moisture. If these

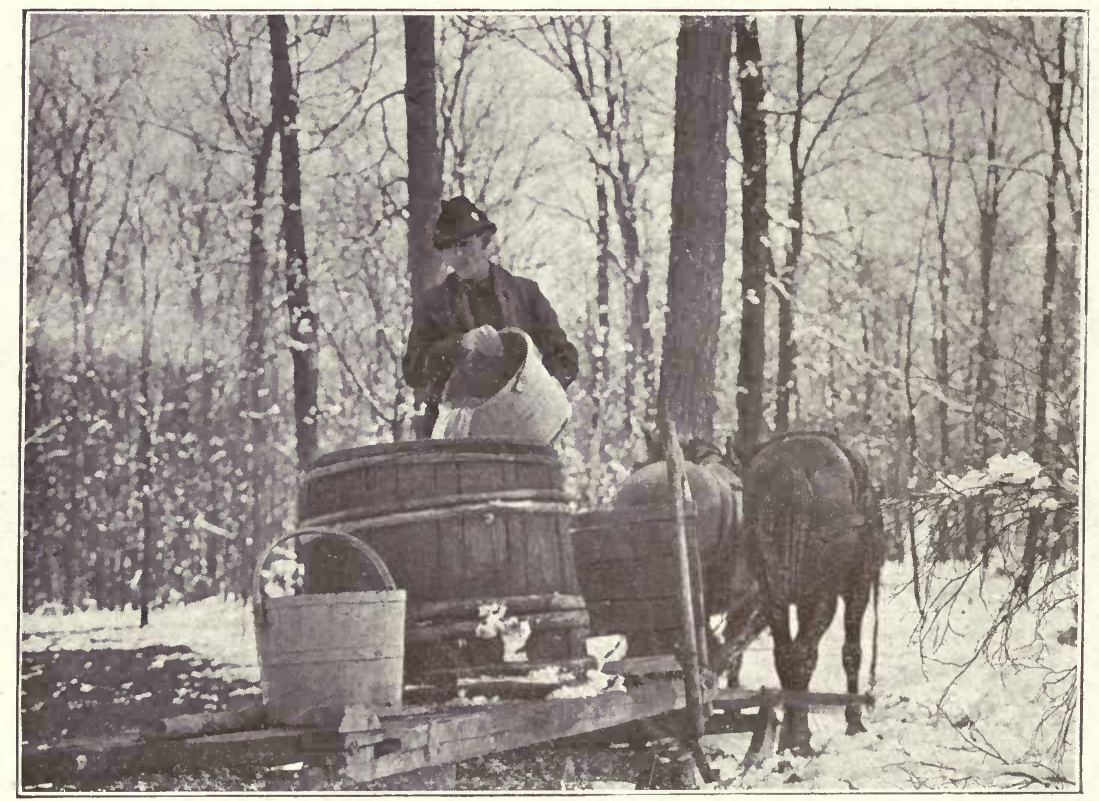

Fig. 8. GATHERING SAP IN THE SUGAR BUSH

Metal gathering tanks are much preferred to wooden ones by the more advanced sugar makers

are injured either by exposure or drought or by the grazing and tramping of animals the tree cannot do its best. For this reason pasturing by farm stock should not be permitted year after year. While the truth of this assertion is generally admitted among sugar makers it is contended by many of them that in order to subdue a too rampant growth of underbrush cattle may be very well allowed to browse the grove about one year in five or six. Unless this is done, or hand thinning is resorted to, the growth becomes so dense and strong that much waste and difficulty is experienced in gathering the sap. It should be borne in mind, however, that for the vigor of the grove as 
well as a full flow of sap year by year it is desirable to maintain forest conditions which include a constant renewal of young trees and a surface kept heavily matted with leaves and humus.

A sugar grove like any other orchard requires some attention to keep it in good condition. Apart from the maintaining of road ways to facilitate the collecting of sap thinning out may be necessary from time to time. In a usual mixture the trees of species other than maple may be gradually removed and the reproduction of the maple encouraged. In making such a thinning the work should be done

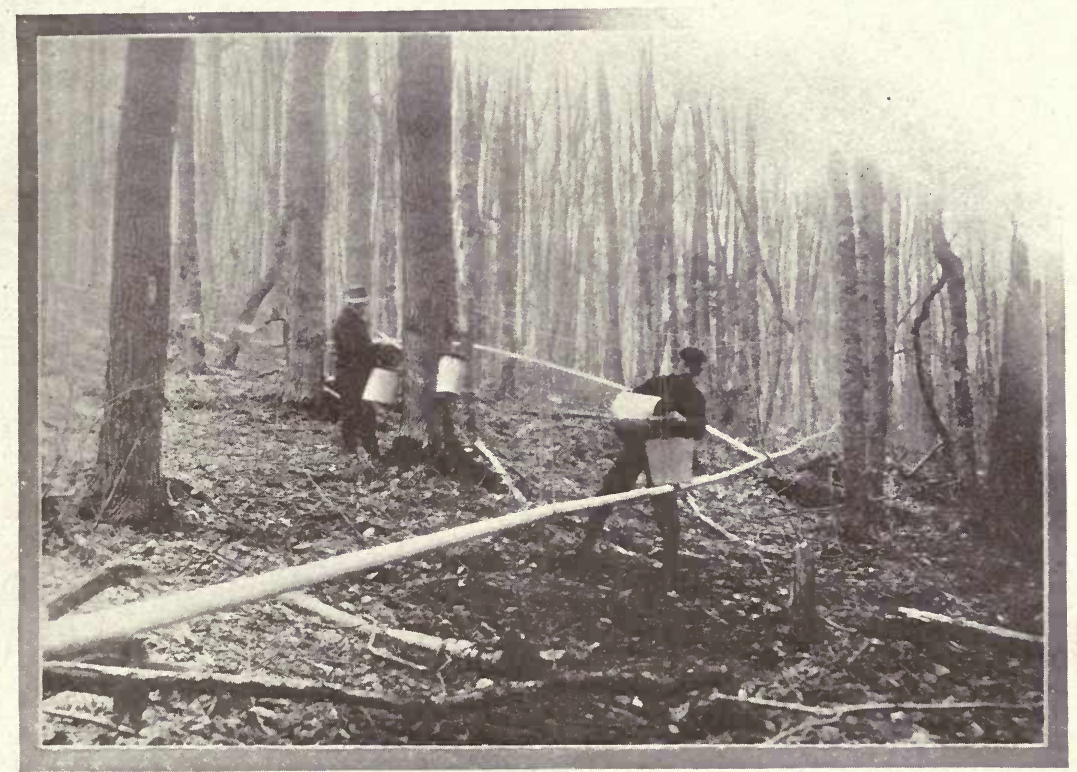

Fig. 9. THROUGH METAL PIPES THE SAP FLOWS FROM THE BUSH TO THE SUGAR HOUSE

gradually, the trees which crowd the best maples being taken out first a few trees from a place at a time so as not to suddenly expose the large maples to danger from wind storms. If the maples themselves stand too thickly those with small crowns or unsoundness should be removed. In their places the promising maple saplings should be given every chance to develop.

$\therefore$ ?

Old groves that have been worked for generations are likely to contain a number of overmature trees that have passed the time of yielding good flows. Unless some attention has been paid to replacing these the sugar orchard is loosing ground, more especially if the 
land be in sod and is grazed by stock. To renew such a grove it is better to bring about a reproduction than to plant a new stand. To accomplish this stock must be excluded soon after which thousands of maple seedlings will be noticed coming up. While these are quite young roadways for sap gathering should be laid out and made smooth. Unsound maples and seedlings and sapplings of other sorts ought to be removed. In a few years the strongest of the sapplings will assert themselves and these should be encouraged by lopping off the tops of the weaker ones. When the preserved saplings have reached

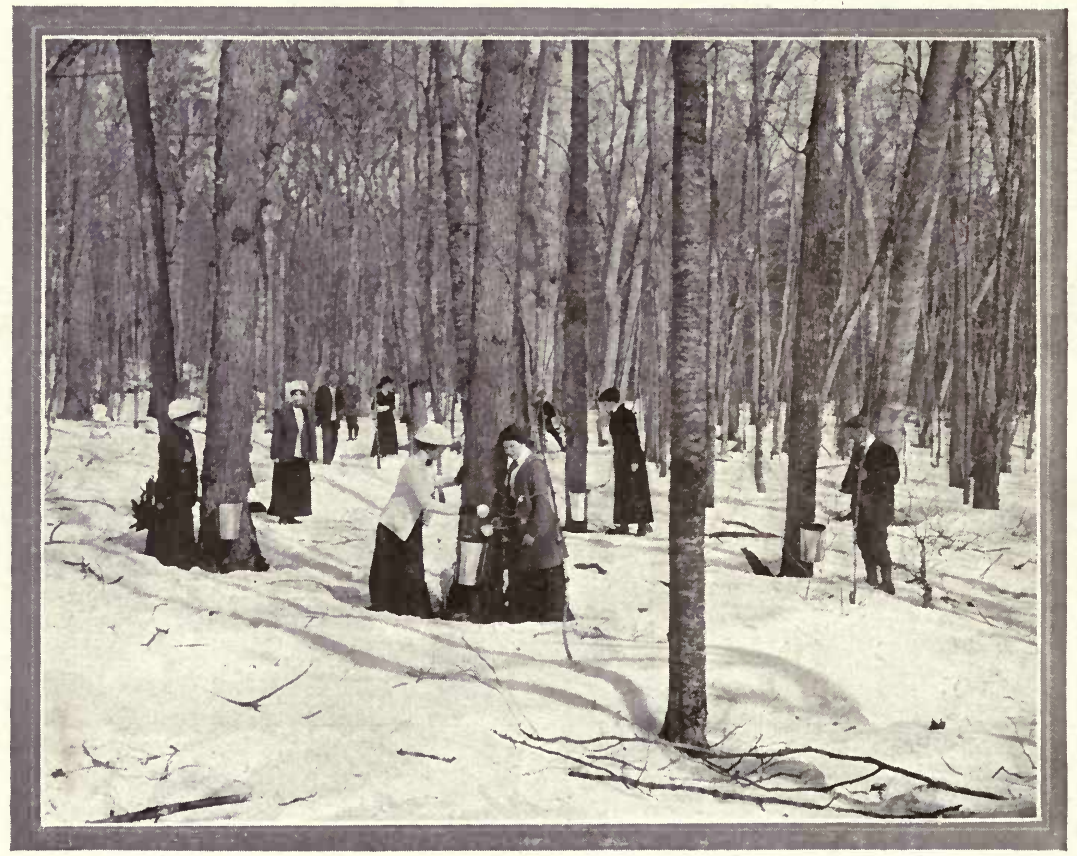

Fig. 10. A Gala day in a SUgar bush at AlgonQuin Park

a height of 9 or 10 feet cattle may be let in to overcome the younger brush which if left would soon make it difficult to collect the sap.

In all this work one has to exercise judgment having in view a highly productive sugar orchard ever increasing in value from the standpoint of the timber alone. Maple lumber has long been a valuable commodity that has doubled in price within little more than a decade. It is only reasonable to expect that ten years hence will see it much more valuable than at the present time. For this reason reforesting with maple should prove a very remunerative enterprise yielding in a few years an annual crop of sugar and a heritage in timber of no mean value. 
Unfortunately the stripping of even our rocky lands of their trees has gone on to an unprofitable degree. A maple tree that will cut two cords of wood is worth on the stump for that purpose about five dollars at the present price of wood and lumber. The annual interest on this sum is from 25 to 30 cents. The tree if left to grow into considerable value for itself will yield an average of three pounds of sugar worth anywhere from 35 to 75 cents according the intelligence of the maker. To clear off the maple timber from stony land unsuitable for farming purpose is like killing the goose that lays the golden egg. It should not and would not be a crime to cut mature trees; but the sin lies in not allowing others to grow. Reforesting with maple is undoubtedly as important as with pine or spruce. In view of the returns to be expected from each of of these kinds of timber there can be no doubt of the real economy of not only conserving the maples on rough lands but also in taking action to reclothe those rugged districts that have been made utterly barren by the loss of the forest.

\section{Reforesting With Maple.}

In the opinion of Mr. R. H. Campbell, Director of Forestry in the Department of the Interior, it is more profitable to reforest with maple than with white pine. In response to an inquiry as to the relative cost of reforesting with maple as compared with pine Mr. Campbell writes as follows:-

\section{DEPARTMENT of the INTERIOR, Forestry Branch,}

Ottawa, May, 5th, 1913.

J. B. Spencer, Esq.,

Editor Publications Branch, Dept. of Agriculture, OTTAWA.

Sir:-

I beg to acknowledge your letter of April 25th asking for a comparison of the maple with the pine or spruce as to the cost and time to bring these trees to a timber size.

In determining the cost of producing any merchantable timber, there are seven points to be considered, viz:-

The value of the land.

Taxation.

The cost of plant material.

The cost of planting.

The cost of management and protection.

The rate of interest on money invested.

The time for the trees to reach the desirable size. 
It has been estimated that white pine planted on sandy waste lands in Ontario will yield, in sixty years, two hundred (200) trees averaging eighteen (18) inches in diameter, or about eighty thousand $(80,000)$ board measure, per acre. In this estimate the land was valued at $\$ 5.00$ per acre; taxation figured at 17 mills; the cost of plants and planting $\$ 10.00$ per acre; the cost of management and protection at 15 cents per acre per year and the rate of interest charged was $3 \frac{1}{2} \%$. The total cost worked out to $\$ 165.34$ per acre. This does not include the thinnings which would probably yield a revenue after the twentieth year and somewhat reduce the cost.

Sugar maple grown under normal forest conditions would yield from one hundred and fifty (150) to one hundred and seventy-five (175) per acre having an average diameter of eighteen (18) inches in about one hundred and fifteen (115) or one hundred and twenty (120) years. Provided all the other items, i.e., cost of land, taxes, etc., were the same, this increase in the length of time alone would raise the cost of growing maple considerably above that of growing pine. The cost of the plants and planting would probably be $50 \%$ more than the $\$ 10.00$ figured on for pine. This is partly due to the heavier nature of the soil in which the maple would be planted and partly due to the higher price for maple seedlings.

It would appear then that if the price of white pine and maple lumber keeps the same relative position (about equal in 1911), it would hardly be a paying proposition to grow maple for lumber alone. However, when one considers the revenue derived after the thirtieth year from the sap and the higher price obtainable for thinnings as fuel, or making acetic acid, wood alcohol and charcoal, there seems but little doubt that the maple would in the end be the more profitable tree. This is particularly true in case of the small woodlot owner or farmer, who has many uses for the wood, and especially where the maple already exists in the stand and natural reproduction can be secured.

Your obedient servant,

(Sgd) R. H. Campbell, Director. 


\section{THE SUGAR MAKING PLANT}

Sap as it comes from the maple tree is a very dilute solution containing from 95 to 98 per cent of water about 3 per cent of sugar and small quantities of mineral constituents. The making of maple syrup or sugar consists primarily in getting rid of the surplus water which, as all sugar makers know, is by evaporation. Early sugar makers used very crude utensils and methods and made as a rule correspond-

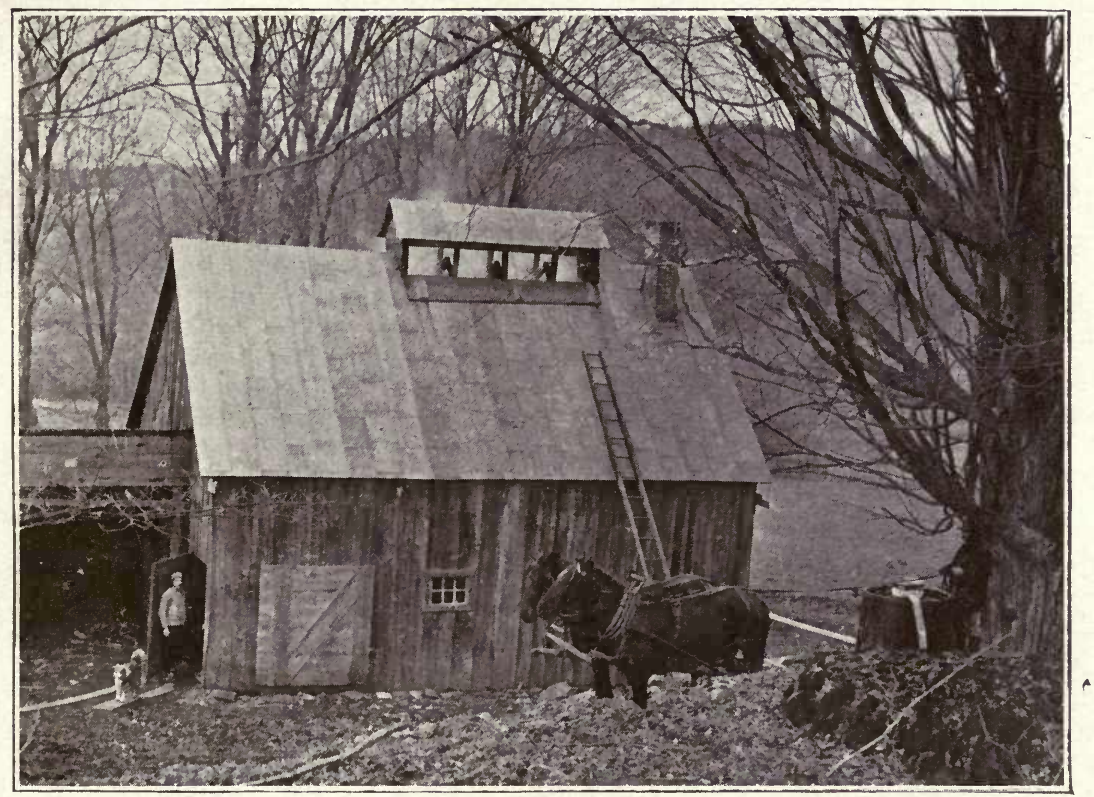

Fig. 11. A SUgar hoUSE IN OPERATION IN MISSISQUOI COUNTY, QUEBEC

ingly inferior products as compared with the high-class goods made on the well equipped and well managed sugar places of the present day. The modern sugar maker recognizes that sap, like milk, is a very perishable product being an excellent medium for the development of fermentive organisms. To make a good sugar or syrup it is necessary, therefore, to have an equipment which will allow for the least possible contamination of the product in all stages of manufacture. Not only must thorough cleanliness be observed but transformation of the new sap to the finished product must be direct and speedy. 
In a paper on tree surgery read at the nineteenth annual meeting of the Vermont Maple Sugar Makers' Association Mr. C. O. Ormsbee described the physiological process of sap elaboration. He said:

"Moisture in the soil dissolves and holds in solution certain mineral elements. This moisture so charged finds its way into the roots of the trees and then into the wood in which it ascends to the leaves through which it passes and from which a very large portion is evaporated, or transpired according to the term employed. It is estimated that a very large tree bearing a big top transpires one hundred and fifty tons of water in a season. From the time the moisture enters the roots until it passes through the leaves it is termed crude sap. But air charged with carbonic acid gas, also passes through the leaves, and meeting with the crude sap yields to it the carbonic acid and emerges as pure air, while the crude sap with its load of carbon becomes

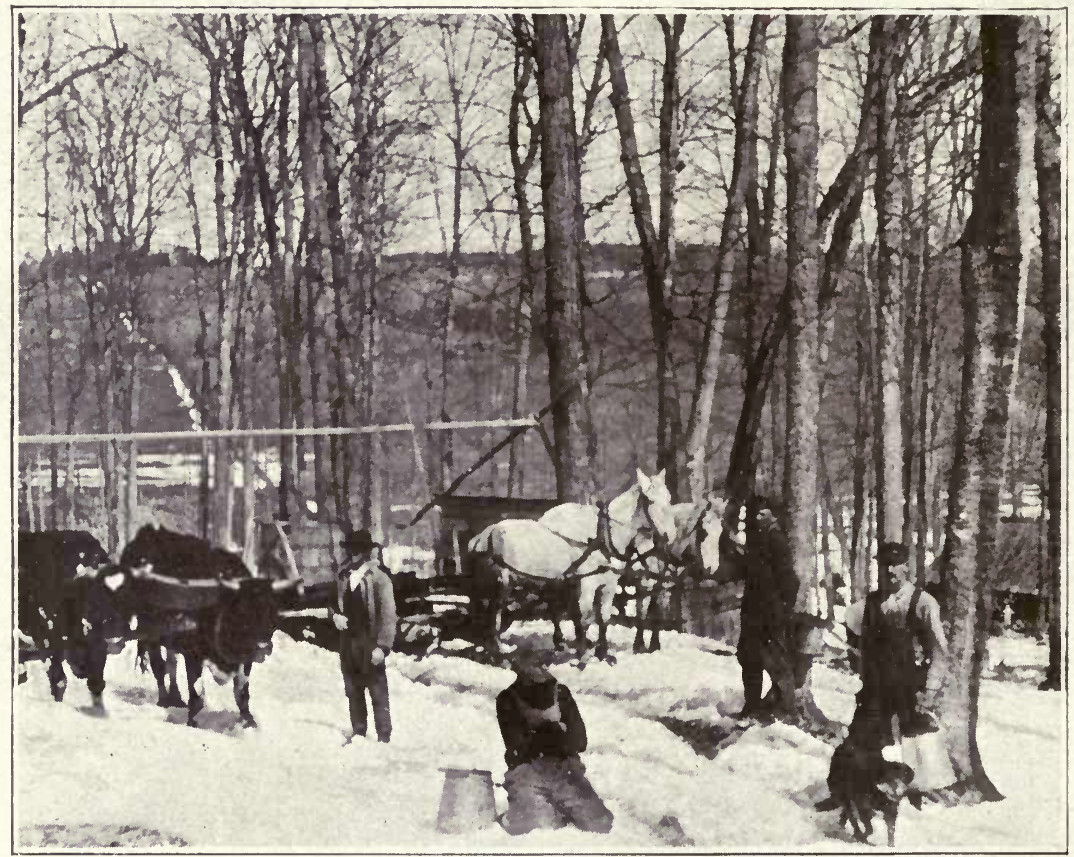

Fig. 12. A SPRING SCENE IN THE MAPI.E COUNTRY

transformed into what is known as elaborated sap. In this form it finds its way back into the body of the tree where it is conveyed in the wood, here and there wherever needed into the inner layer of the bark which is called the cambium and where it is transformed 
into the wood which forms the season's growth. The greater part of this sap, however, and perhaps all of it is this elaborated sap that we use in making syrup and sugar from the maple tree, and tar and turpentine from the pine tree."

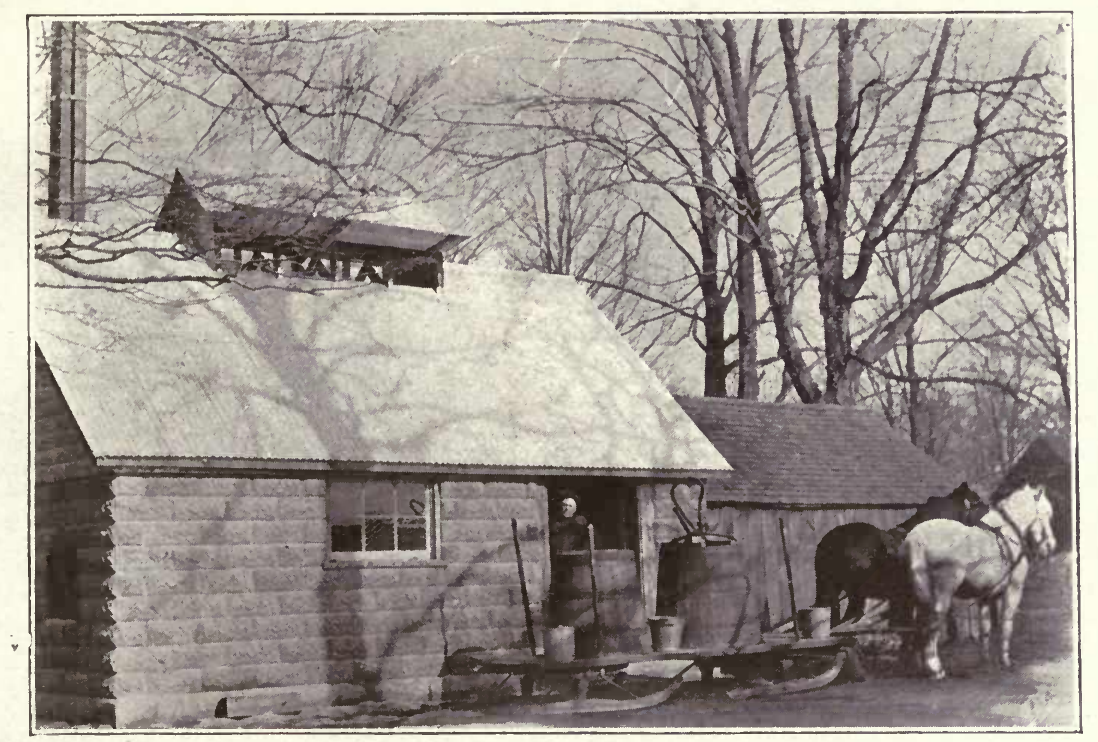

Fig. 13. A CEMENT CONCRETE SUGAR HOUSE IN WESTERN ONTARIO

The Sugar House.

The sugar house of a modern plant is not only for making and putting up the products but also for storing buckets, pails, spouts and other equipment from one spring to another. What appeared to be the best sugar house visited in the Eastern Townships was constructed to take care of the flow of about one thousand trees. It is $42 \mathrm{ft}$. long and $30 \mathrm{ft}$. wide. The walls were well built of house siding and painted; the floor is of cement and the ceiling of shingled wood. It has a leanto $12 \mathrm{ft}$. wide on the east side for storing wood and a small compartment at the north end for protecting the storage tank. It is built on sloping ground so that the gathering tank empties by gravitation into the storage tank and from there into the evaporator. Where the location is level or nearly so it is the usual custom to build an elevation on which the hauling sled may rest while the collected sap is flowing out to the sap holder. Other sugar houses have metal 
roofs but these are apt to drip during boiling which is not only un pleasant for the workers but tends to color the sap in the evaporator. On this account a shingled roof is preferred. It is well to have the walls fairly tight and ventilators of large capacity, the full size of the evaporator, to allow the steam to escape freely. It is well understood that the warmer the house the better the ventilation. A cold sugar house is generally filled with steam while in operation. The house should be well lighted. A brick or metal smoke stack should extend well above theroof to assure a good draft as hot fires are necessary

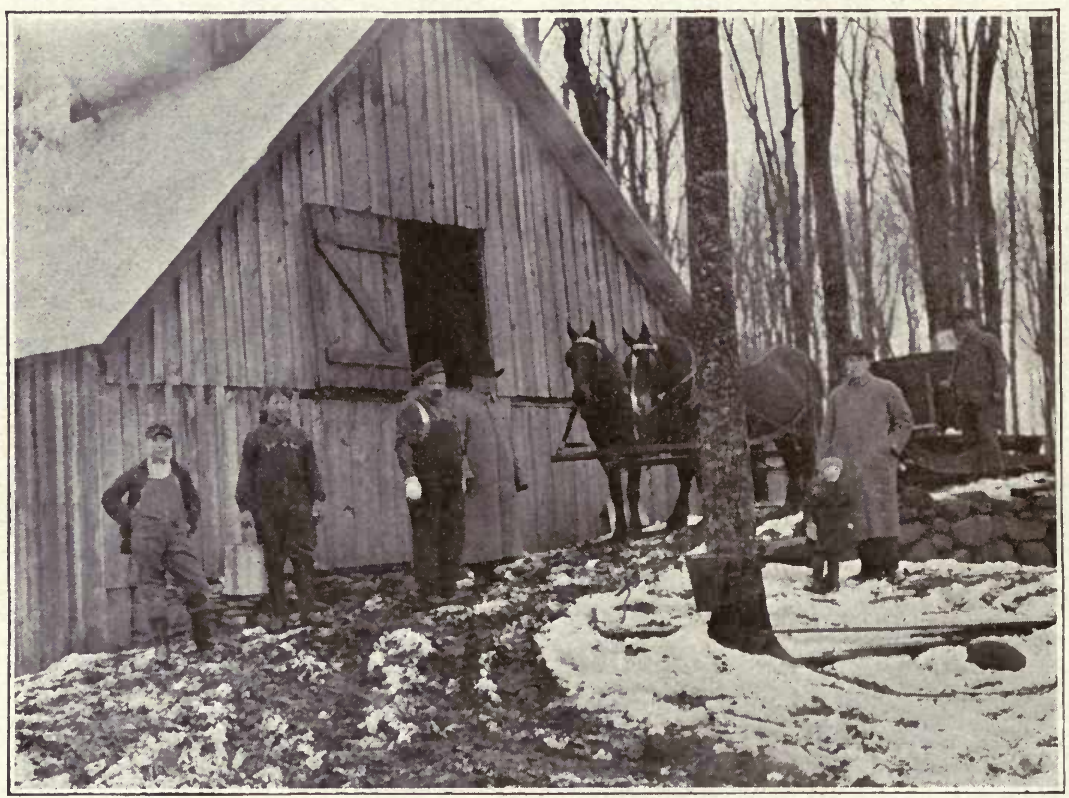

Fig. 14. A LOAD OF SAP ARRIVING AT THE SUGAR HOUSE ON A SIXTEEN HUNDRED TREe SUGAR ORCHARD IN COMPTON COUNTY, QUEBEC

to good work. If the floor is not wholly of cement it is well for protection from fire to use cement or brick pavement in front of the fire doors. A drain leading away from the building should be provided to carry off weather water and washings.

The building of the sugar house should be finished during the Summer or early Autumn so that the furnace or arch may be placed on its foundation before the ground is frozen. The equipping, including the storing of a supply of fuel, should also be concluded before winter sets in. 
The Evaporator.

It has been a long stride from the iron kettle, used in sugar making by our forefathers, to the modern evaporator that is necessary for the making of a high priced product. In pioneer days the saving of fuel had not to be considered nor was quality of product a live issue. Most settlers had kettles for the making of potash which in many districts was the only crop for which money could be exchanged. These large iron basin-like vessels served for many years to boil down

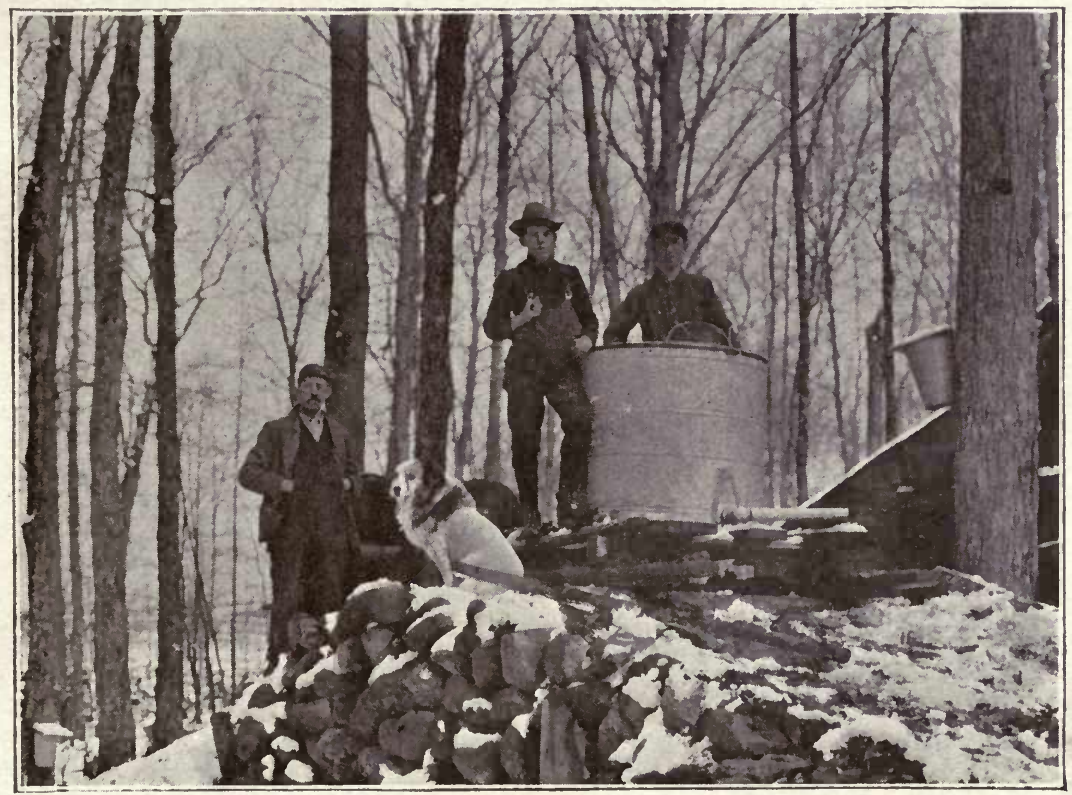

Fig. 15. A GATHERING TANK DISCHARGING ITS LOAD OF SAP AT THE SUGAR HOUSE

the sap and because only dark and strong flavored goods could be made in these it has taken a long time for the public to recognize the superiority of the lighter, cleaner, milder sugar turned out by the modern evaporator.

An advance on the old kettle was the flat-bottomed sheet iron pan 2 to $3 \mathrm{ft}$. wide and 2 to $6 \mathrm{ft}$. long built over a brick or stone fireplace. Some of these pans are still in use in back districts that have never looked for more than a low price for their inferior products.

The modern evaporator is designed for rapid evaporation and economy of fuel. There are several makes in use but all are similar 
in principle. It consists of a heavily tinned pan strongly made set on an arch which usually has a regular stove front with large doors for firing. The pans have corrugated bottoms and are partitioned off to give a zig zag course to the sap. It is important that it be set quite level so as to maintain a uniform depth of sap. Most of them are equipped with a float feed which allows the fresh sap to flow in as
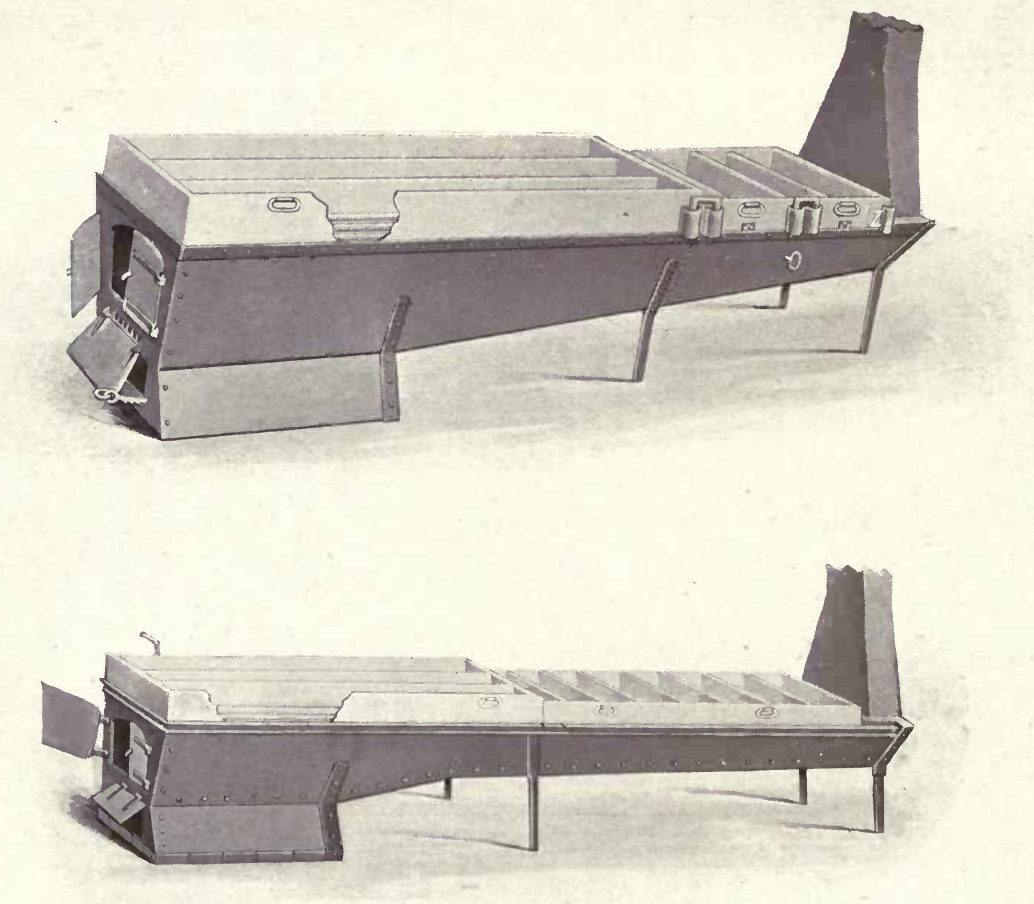

Fig. 16. TYPES OF MODERN EVAPORATORS All have corrugated bottoms

rapidly as the water evaporates. The sap enters at one corner usually at the front and by a zig zag course flows from 80 to 100 feet before reaching the outlet at the other end. The sap thickens as it flows and has to remain in the last compartment only a very brief time before it has reached the consistency of syrup. From here it is drawn off at frequent intervals.

When purchasing an evaporator it is important to provide for expansion of the plant and the taking care of heavy runs of sap. An experienced maker believes in providing ten square feet of boiling surface for every one hundred trees tapped. 
For reducing syrup to sugar an additional evaporator is necessary. This is a simple pan 2 to $2 \frac{1}{2} \mathrm{ft}$. wide by 3 to $6 \mathrm{ft}$. long and about one foot deep. The metal is usually of heavy tin or in some cases galvanized iron but never of sheet iron. This pan sits over an arch or firebox. It has convenient handles for lifting it off the fire when the syrup has reached the proper consistency to crystallize. Some
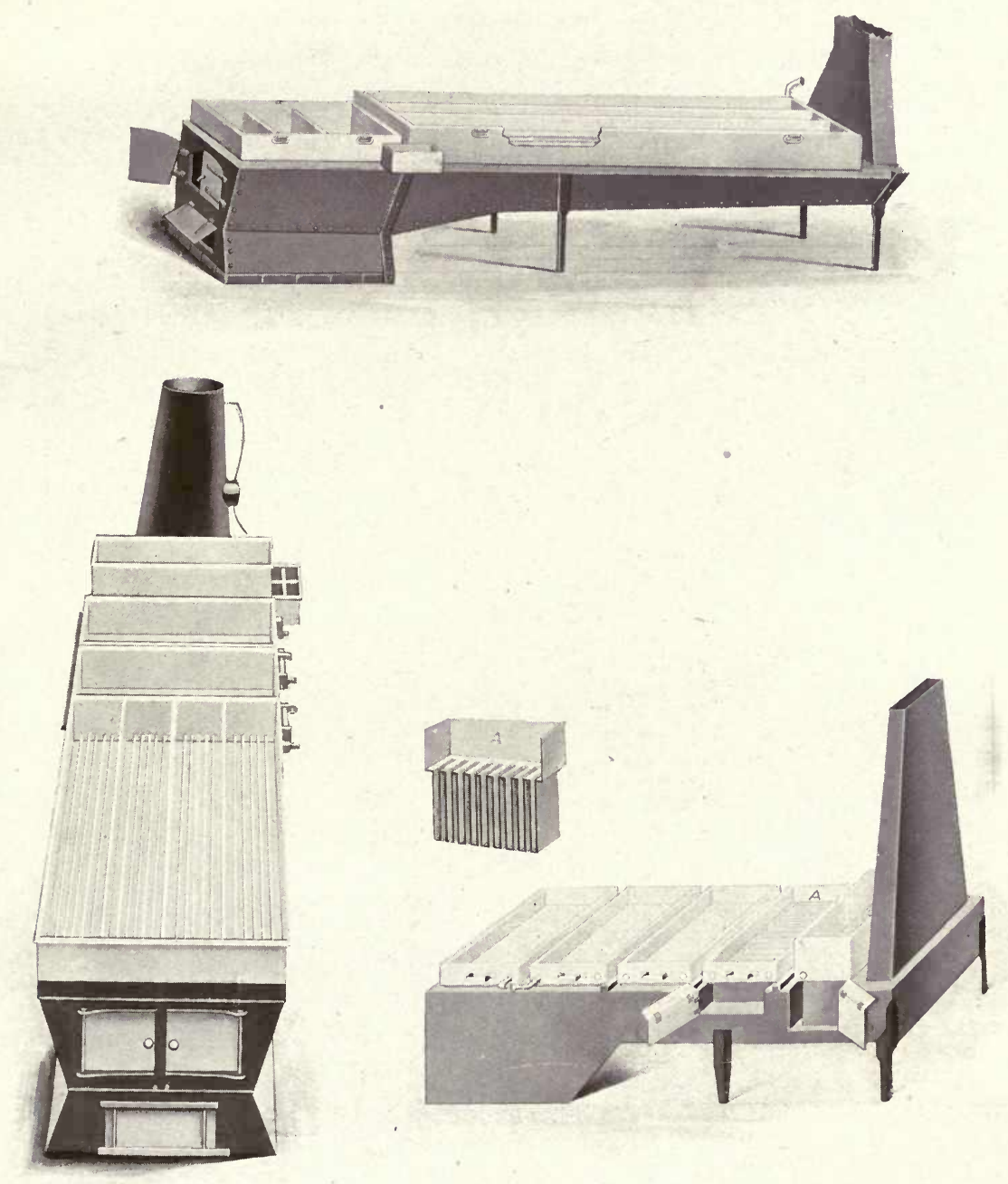

Fig. 17. TYPES OF MODERN EVAPORATORS

All have corrugated bottoms

makers use a block and tackle for raising this pan from the fire. This is necessary where one man has to do the work alone. 


\section{OPERATING THE PLANT}

Sap will flow during favorable weather anytime after the leaves have fallen in the autumn, but even though a warm spell should occur during the autumn or winter no experienced sugar maker thinks of tapping his trees. The proper time to tap varies from year to year and in different latitudes. In Canada it seldom commences before March and is not often delayed beyond the first of April. It should

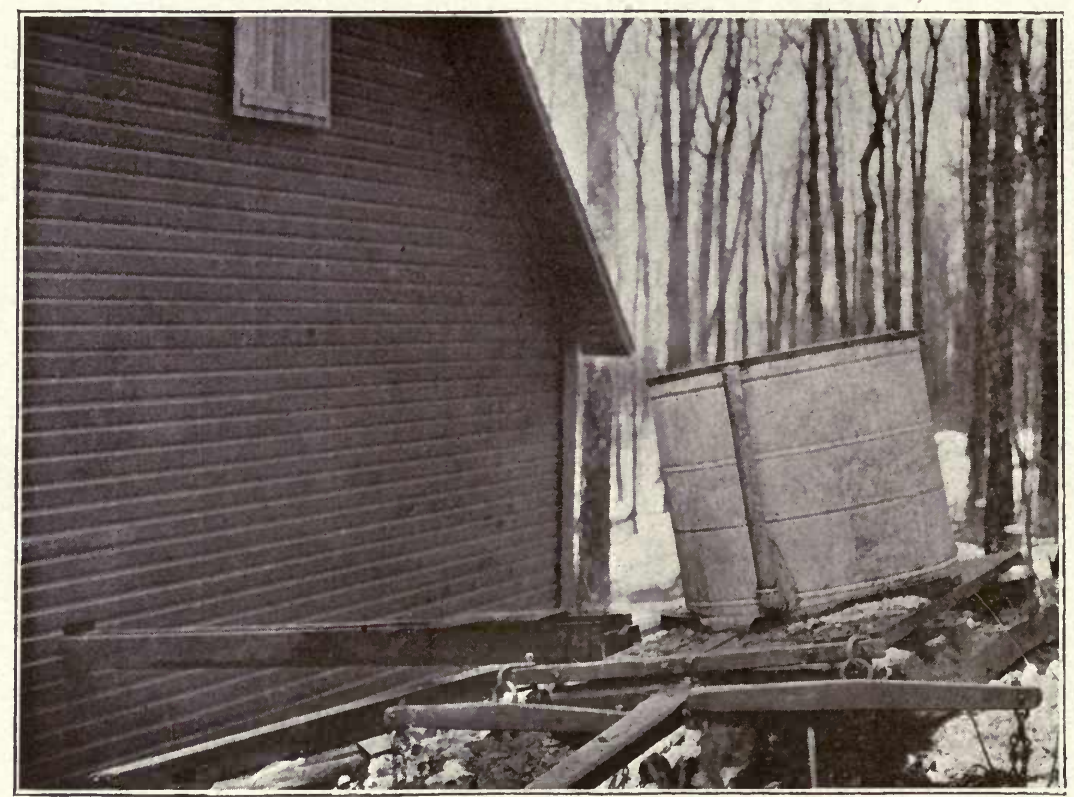

Fig. 18. A MODERN GATHERING TANK READY TO BE EMPTIED AT THE SUgAR hOUSE

be done when indications point to warm, sunny days and frosty nights. A sugar maker living in the Eastern Townships of Quebec kept a record of tapping dates since 1884. During this period the earliest tapping date was in 1894 when it commenced on March 9th. The latest season was in 1912 when tapping did not take place until the 9th of April. In 1903 the season ended on April 2nd and in 1911 on April 26th. which were the earliest and latest finishing dates on this farm.

At the beginning of the season all the sugar utensils should be cleaned even though they were well washed, dried and stacked away at the close of the season before for the dust which collects during the 


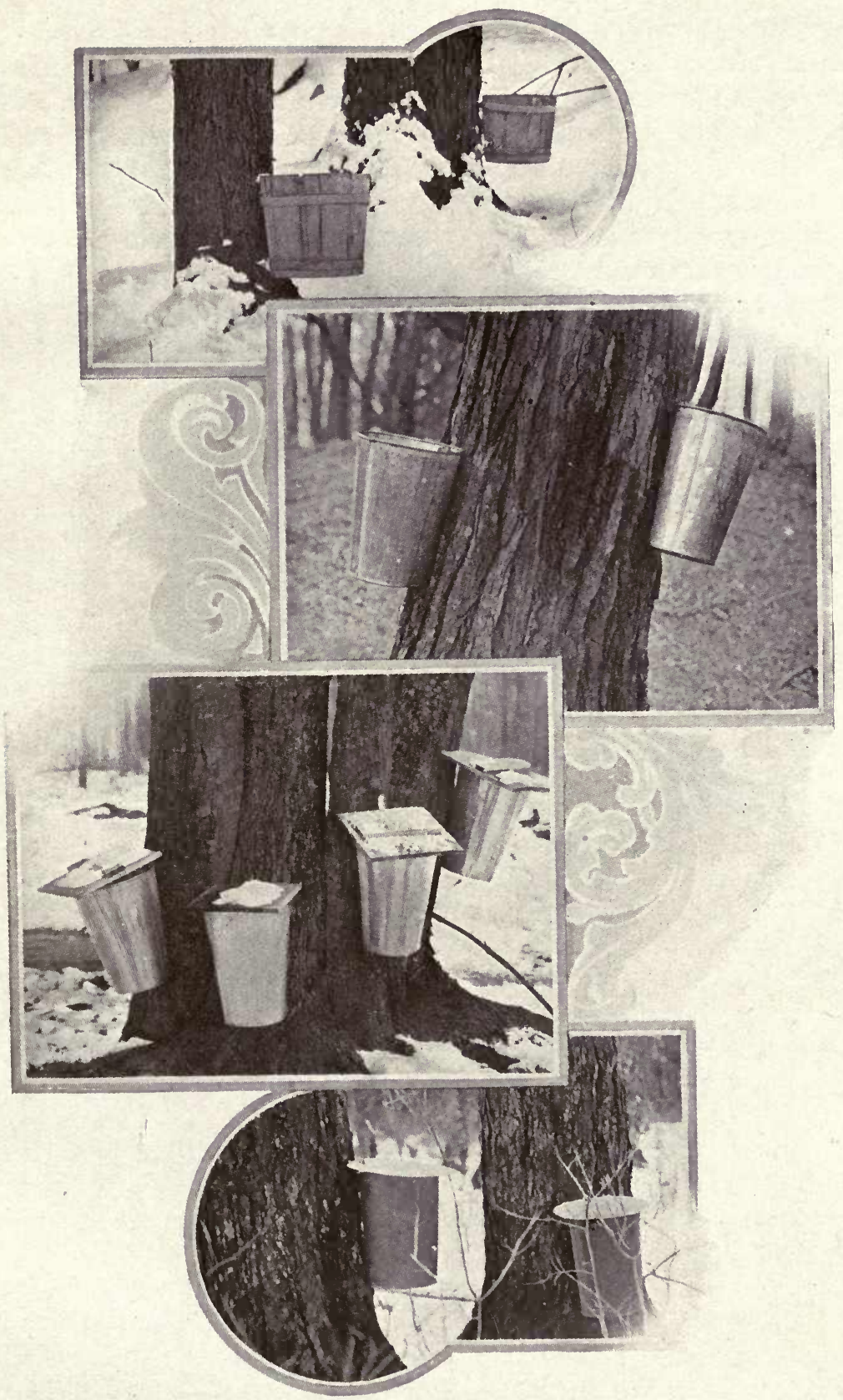

Fig. 19. SAP BUCKETS RECEIVING THE RUN

The wooden bucket shown in the uppermost scene is no longer used by the careful maker. The lower scenes show wooden and metal bucket covers. See page 32 . 
year would damage the first run of sap considerably. Utensils that have become rusty should be discarded or painted. If painted on the inside they should not be used before the following season because freshly painted buckets have a strong tendency to taint the sap.

Having distributed the buckets and spouts the tapping is begun. In the early days it was the custom to tap with an axe, then came the large auger which held sway for a long time as makers were slow to find out that as much sap could be secured from a small as from a large hole. Sap is forced out by internal pressure, and a very small opening will relieve that pressure causing the sap to flow as rapidly

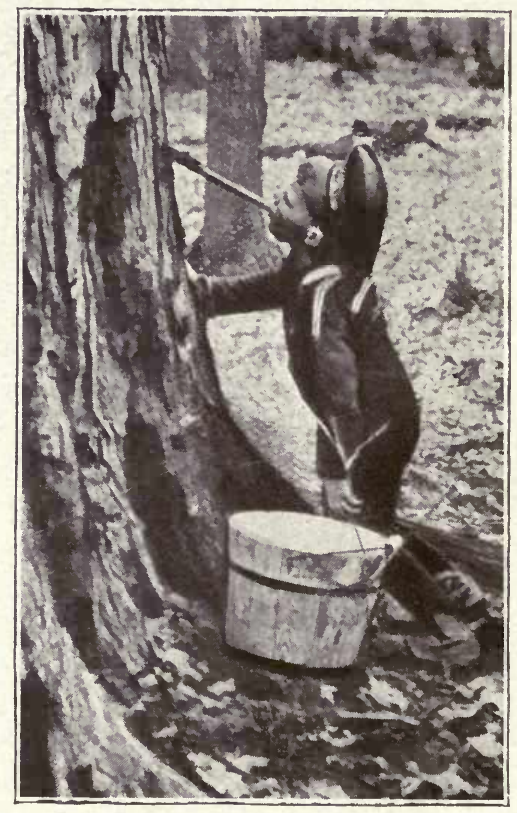

Fig. 20. A JOY OF SPRING

as from a larger hole. If the tree is tapped again on the opposite side the pressure in another area is relieved and more sap is secured but not twice as much, another tapping will give still more sap in the aggregate and so on in a decreasing ratio.

As a general rule a tree is tapped at only one point but it is not uncommon for a large tree to carry two vessels or even three which is quite exceptional and not recommended.

Tapping is usually done with a three eighths, seven-sixteenths or half inch bit. The hole is bored in a slightly upward direction about $1 \frac{1}{2}$.in. deep in a medium sized tree to $2 \mathrm{in}$. in a large one. The point 
of tapping should be about 30 inches from the ground where the bark has a healthy look, and some distance from an old hole. Only the rough loose bits of bark should be removed from about the hole. The hole should be clean cut so as not to bruise or tear the wood or bark. All chips and bark should be carefully removed from the hole before inserting the spout.

\section{Spouts.}

Many types of spile or spout are used but it is generally agreed that it should be of metal and of such material as will not corrode or prevent a free flow of sap. It should be perfectly round and slightly tapering so as to fit the hole so firm'y as to hold a full bucket of sap suspended from it. The spout should exclude the air from the hole
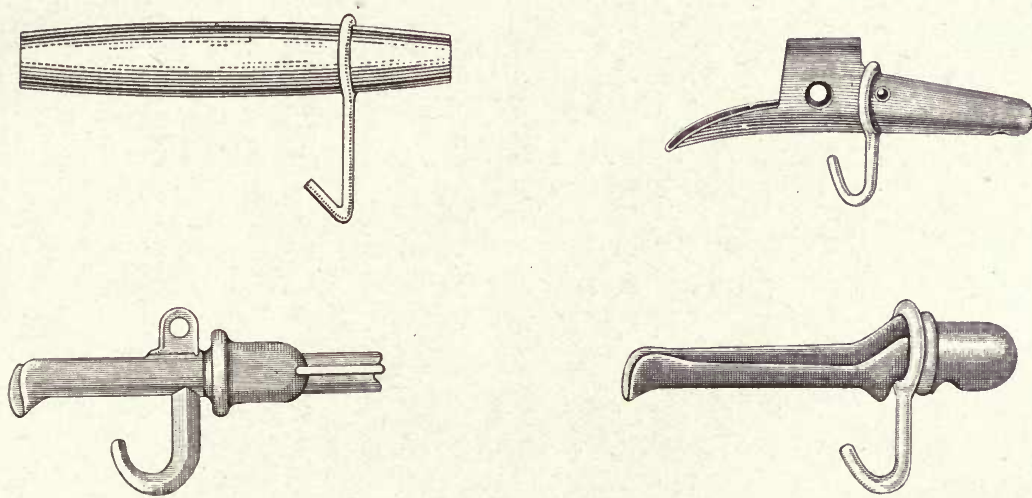

Fig. 21. TYPES OF SAP SPOUTS

The upper left hand one is of wood; the others of metal. Wooden spouts are not in favor with the best makers.

as far as practicable so as to guard against drying up or the retention of sap to sour during a warm spell or freeze when it is cold. The inlet for the sap should therefore be near the bottom of the spout so as to drain completely at each cessation of a days flow.

\section{BuCKETS.}

There are several kinds of buckets, but to make the very best sugar and syrup, as well as to exercise economy, one should use only tin buckets of good quality. Galvanized iron buckets should never be used, as they discolour the sap, moreover being coated with poisonous metal-zinc and lead, they are obviously objectionable. They are very difficult, in fact almost impossible, to repair when old, and 
are hard to keep clean. The only redeeming feature of a galvanized iron bucket is that it will not rust. Many people still cling to the old fashioned wooden buckets, but they tend to discolour and sour the sap and injure the tree, requiring an extra spike driven into it to hold the bucket. They are also difficult to keep clean and when handling may fall to pieces. A painstaking maker claimed to have used for 40 years a set of wooden buckets and made good sugar but he took the precaution of painting them inside and out every few years. New wooden buckets are now a thing of the past.

Because sap should be gathered frequently a very large bucket is not necessary. From 8 to 12 quarts is the usual range the largest size being necessary only for trees farthest from the house where the gatherer is likely to miss occasionally.

\section{Covers.}

The bucket cover is by no means a new thing but Canadian sugar makers have been slow to adopt it. In sections of Vermont covers have been in constant use for more than twenty years but comparatively few Canadians have seen fit to put them on. In seasons of little storm during the making season covers may not be necessary but after the spring of 1913 , in which March was a stormy month, every one will admit the value of bucket lids. One farmer with a thousand trees tapped made $600 \mathrm{lbs}$. of sugar while his neighbor running an equally large plant poured out every particle of sap during the same period because he had no covers. Another without covers got only $90 \mathrm{lbs}$. of sugar from 290 pails of sap and storms water that should if of pure sap have yielded $290 \mathrm{lbs}$. Besides having to use three times as much fuel as should have been necessary his sugar was dark, poor stuff due to long boiling and washings from trees. Covers not only keep out storm but also bits of bark, moss, leaves and dead insects that are constantly being driven about whenever the wind is blowing. Covers are made of tin and of wood; illustrations of both kinds are shown at Fig. 19. The cover should not lie flat on the pail but allow for an air space between the cover and the top of the bucket so as to ventilate the latter and thus avoid souring the sap. Makers in Quebec and Eastern Ontario who used covers in the spring of 1913 paid for them several times over in the increased crop and improved quality of the products. In certain counties of Western Ontario covers have been in use for several years and most of the makers now have them. These men from their comparatively small groves make goods of excellent quality for which they secure very good prices. 
As the season advances and the days become warmer fermentation is sure to take place in the vessels, causing the sap to sour and slime to accumulate about the spouts, buckets, pails and tanks. To continue making a fine product it is necessary to draw the spouts and ream out the holes so as to expose a fresh surface of wood. Some recommend boring a new hole a few inches from the old one and claim to get better results. At this stage all utensils should be scalded or washed with hot water. By carrying out these precautionary measures the season may be prolonged without the risk of making "buddy" products.

The Vermont Agricultural Experiment Station has recently published a bulletin of 600 pages describing studies made by the officers of the Station on the influence of micro-organisms in spoiling sap. They conclude that although there is really such a thing as "buddy sap," that is to say sap the flavour of which has been injured by the physiological changes occurring in the tree as it resumes its summer activity, yet most of what is called "buddy sap" is really sap spoiled by microorganisms, which find conditions particularly favourable to their growth during the warm weather toward the end of the sugar season.

\section{Gathering the Sap.}

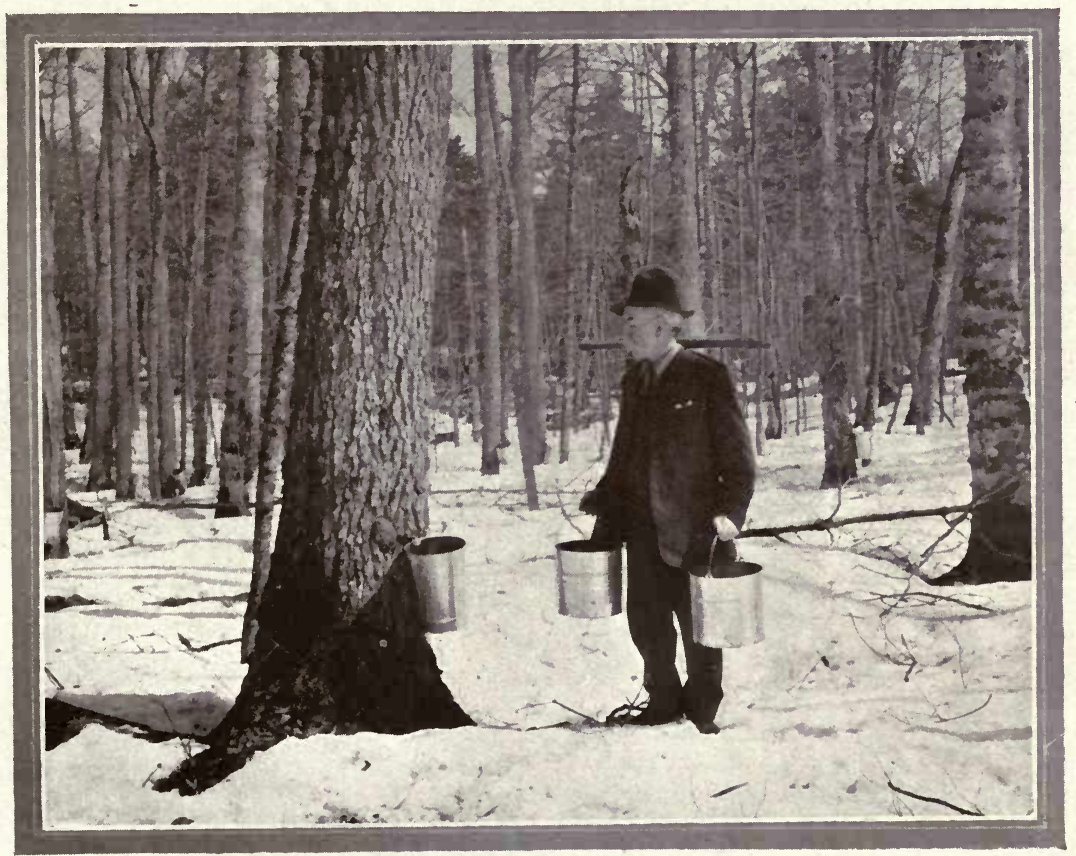

Fig. 22. THE SAP GATHERER MAKING HIS ROUND Note the Yoke for carrying the pails 
The sooner the sap is turned into syrup or sugar the better will be the product. Sap deteriorates very quickly after it leaves the tree. For this reason gathering should commence as soon as there is a quart or two in the buckets.

Gathering pails for carrying the sap from the trees to the tank are frequently of wood, but heavy tin is better because it is more easily kept clean. For convenience in carrying sap these pails should have wide bottoms and narrowar tops.

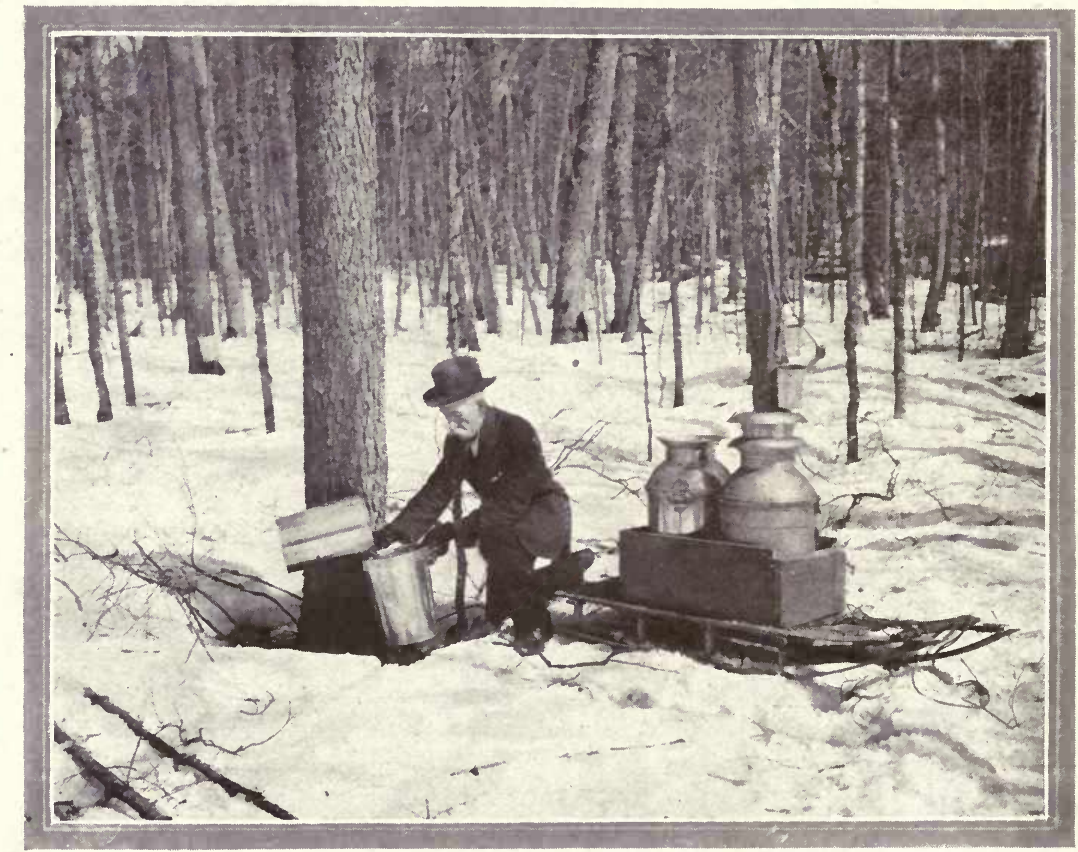

Fig. 23. THE HAND SLED AND MILK CAN USED IN GATHERING SAP

The tank for hauling the sap to the sugar house is mounted on a wooden shod sled. A rectangular hauling tank is not to be recommended because the sap dashing from end to end while driving over rough ground soon racks it to pieces. For this reason it should be circular in form and made of heavy tin or galvanized iron, with a reinforced wooden bottom. A tank holding from 75 to 100 gallons is a convenient size for a 1,000 tree grove.

The outlet at the bottom should be from two to three inches in diameter, so as to let the sap out quickly. A length of cotton hose or piece of pipe a little longer than the height of the tank should be fitted 
into the outlet. When gathering, this hose or pipe can be fastened to a hook in the top of the tank. To empty the tank let down the pipe and insert it into the pipe leading into the storage tank.

A double cloth strainer should be fastened over the entire tank to keep out all dirt. This cloth should be thoroughly cleansed after each

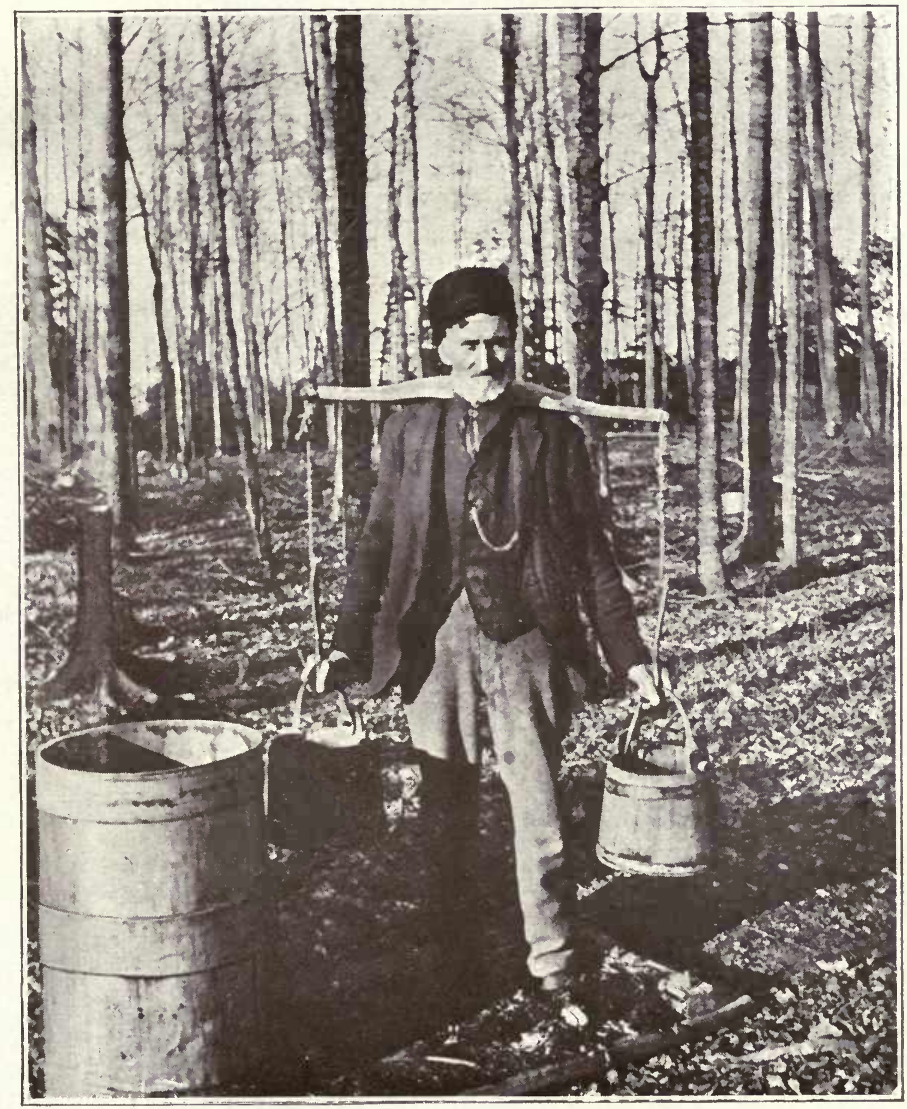

Fig. 24. A SAP GATHERER AND HIS OI.D-FASHIONED OUTFIT

gathering. It is well also to again strain the sap through two or three plies of cloth as it leaves the gathering tank for the storage vat.

If the sap could run directly from the tree to the evaporator the ideal condition would obtain, but obvious obstacles prevent this desirable result. A storage tank is necessary to keep the evaporator going between loads of sap. Because stored sap quickly deteriorates a large storage is not necessary, that is provided a sufficiently large evaporator 
is used. In order to keep the sap cool this vat should stand under a roof on the north side of the sugar house. In a warm time it is well to have a supply of ice to place in the sap to keep it cold.

The sap holder should be of heavy tin plate supported by an iron or wood frame. As already pointed out, it should be placed high enough to drain into the evaporator.

\section{A Supply of Fuel.}

A proper supply of fuel is a matter of the utmost importance in sugar making. A quick flashing blaze is necessary to rapid boiling, and this can be obtained only with dry fuel. Wood is used almost universally, but in some cases coal is utilized to help out. Makers near saw mills find great satisfaction in the use of slabs. Whatever wood is used should be cut the previous winter, piled out of doors during the summer to dry well and stored, before Autumn rains commence, in the wood shed adjoining the sugar house. Cord wood and small brush go well together, the latter to keep the blaze bright and lively.

The amount of fuel that will be needed depends upon its kind and dryness. Ten cords of mixed hard and soft wood for 1,000 trees, or 35 cords for 4,000 trees are recommended by experienced makers.

\section{BoIling the SaP.}

As soon as sufficient sap has been gathered to keep the evaporator in operation, preparation should be made for boiling. To hold sap for an unnecessary length of time in the storage tank is to lower the quality of the product. Before starting the fire enough sap should be run in the pan to cover the bottom to a depth of from one-quarter to half an inch above the corrugations. The shallower the sap in the pan the more rapid will the sap be converted into syrup and the better the product. Fresh sap boiled immediately in glass vessels gives a light coloured, delicate flavoured syrup, but if the syrup is diluted with water and again thickened by further boiling, the colour becomes darker and darker and the flavour stronger and stronger the more times it is diluted and concentrated. The same undesirable result is obtained by boiling the sap deeply in the pan as this keeps the sap longer over the fire as was done in the days of the old time potash kettle.

For rapid boiling part of the wood should be cut short enough to go across the fire box. When firing it is well to lay a stick crosswise at each end and then lay a single layer of wood on the top of these sticks; then another pair crosswise and another layer on top, continuing until the box 
is within about 8 inches of being full, then close the doors. The fire box should be deep enough and the wood fine enough to allow for three or four tiers of wood and still leave space under the pan. This is important, as it allows the fire to roll over and over, giving off the utmost heat to the pan. In firing the fuel shoul $l$ be thrown in very rapidly so as to keep the doors open as short a time as possible, as the inrush of cold air when the doors are open quickly cools the pan and delays the evaporation.

The nature of maple sap is such that by boiling there is a natural cleansing of the product. A coagulation of albuminous matter first occurs

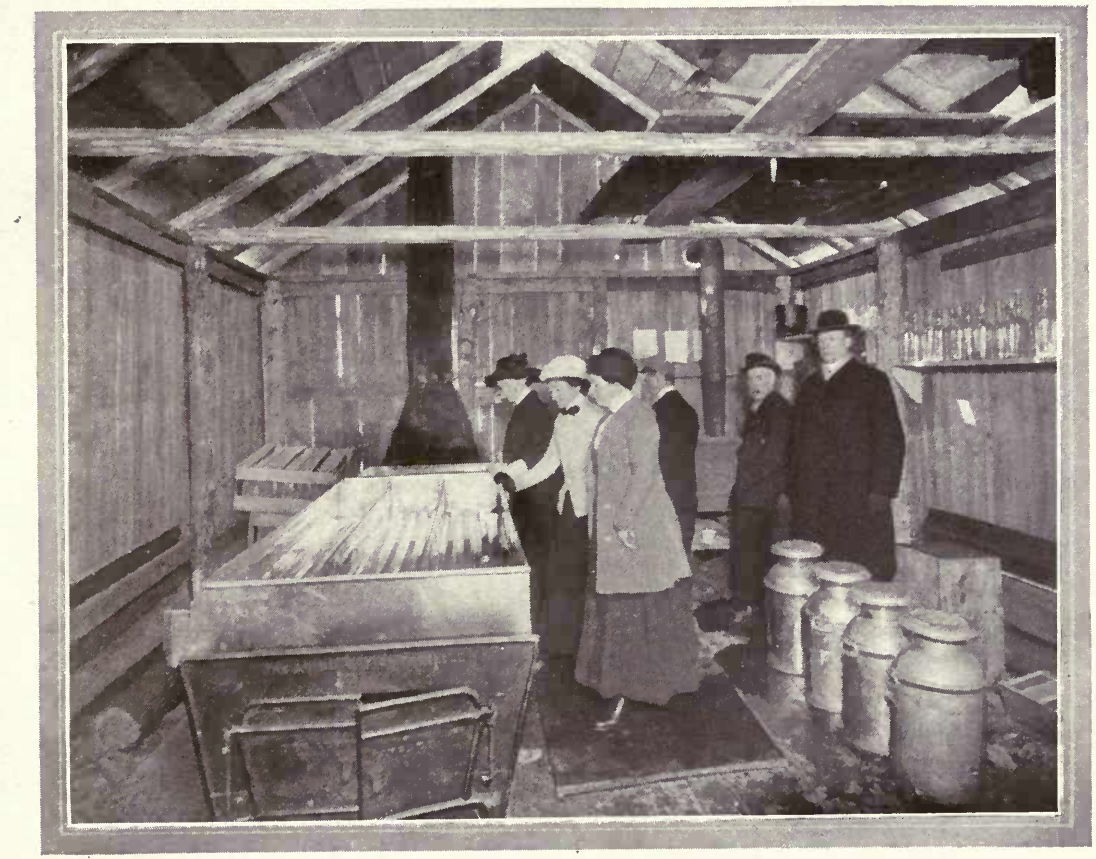

Fig. 25. VIEW OF INSIDE OF SUGAR HOUSE

and this rise as a scum bringing with it other solid matter. As all sugar makers are aware, it is highly important that this scum be removed as it forms by means of a skimmer which resembles an ordinary house dustpan, having a somewhat longer handle and perforated bottom.

After boiling has proceeded for a time the depositing of mineral matter variously known as sugar sand, silica, malate of lime and nitre, commences.

This comes about by a concentration of the mineral salts to a point when they will no longer remain in solution. By the time the syrup 
has reached a consistency to be drawn off much of this mineral product has become a sediment and can be taken out by straining the hot syrup through a strainer of felt or several thicknesses of flannel. Makers

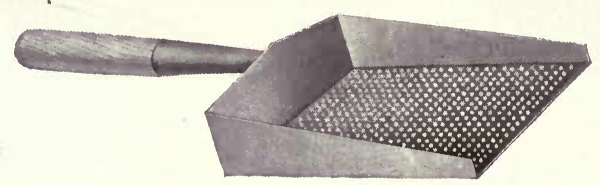

Fig. 26. SKIMMER FOR REMOVING SCUM FROM BOILING SAP

of syrup resort to other means of removing this sediment, the addition of such agents as white of eggs, milk, baking soda, etc, being the principal methods. An old sugar maker considers that one egg or one half pint of milk is sufficient to cleanse twenty to twenty-five pounds of sugar. It is a question whether or not these and similar substances when added to syrup do not injure the keeping quality. The more advanced makers are finding out that these are not so necessary as they were thought to be. By the use of cleanly methods and the proper handling of a modern equipment which includes felt strainers the goods are turned out pure and clean and of good keeping quality.

SYRUP.

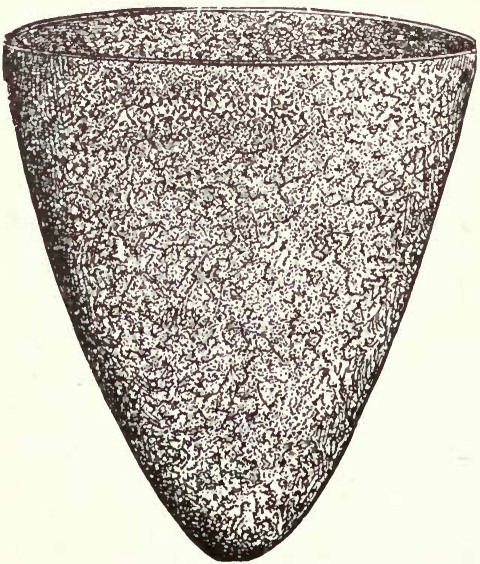

Fig. 27. FELt SYRUP STRAiner

The syruping off point is a delicate one upon which the greatest care must be exercised. If not heavy enough the syrup will sour, and if too heavy it will crystallize in the storage vessel. With careful 
work and the use of the thermometer or saccharometer it can be determined with accuracy. If the work is to be completed in the evaporator the syrup should be drawn quite frequently from the final compartment as it reaches the proper consistency. Continuous drawing off would be the ideal system but good results are achieved by removing the syrup at 10 to 15 minute intervals. Many makers prefer to use a separate arch and pan for finishing the syrup. In such cases the syrup is drawn from the evaporator before the final density is reached. Uniform density can be maintained more easily in this way and by having an extra pan the sugar maker may always have a clean one in readiness and by turning a damper in the arch it can be adjusted without trouble from smoke or ashes. The nitre coated pan can be easily cleaned by keeping it under running water for a while or by allowing sour milk to stand in it over night and thorough washing and scalding in the morning.

\section{Testing The Density.}

Most Canadian makers use the thermometer for judging when the syrup has reached the correct density. The boiling point of liquids varies with their density and with the altitude above sea level. At sea level water boils at 212 , syrup at 219 , soft sugar at 233 to 240 and hard sugar at 242 to $245 \mathrm{deg}$. Fahr. The boiling point for each of these is lowered one degree for about $550 \mathrm{ft}$. ascent. Since sugar groves are usually at some height above sea level it is necessary for accuracy to test the thermometer in boiling water. At whatever degree the water boils there should be added for syrup 7 degrees, for soft sugar 26 to 28 degrees and for hard sugar 30 to 33 degrees. If, therefore, water boils at 210 degrees the syruping temperature would be 217 , the soft sugar temperature 236 to 238 , and the hard sugar temperature 240 to 243 degrees each in a state of boiling. Consequently when the boiling syrup reaches these respective figures on the thermometer it is sufficiently dense to be drawn off for the purpose desired.

The saccharometer or hydrometer is used for testing the density of the syrup either hot or cold. For testing boiling syrup the liquid is poured into a vessel two inches in diameter and nine inches deep and the saccharometer promptly placed therein. When the syrup is of standard weight the instrument will register $30 \frac{1}{2}$-degrees... If it registers less the syrup is too light and if more too heavy. In cold syrup of proper density, at say 70 degrees, the saccharometer should settle to $35 \frac{1}{2}$ degrees. Before making either the hot or cold test the instrument should be brought to approximately the same temperature 
as the syrup to be tested. In making syrup the use of an instrument is necessary for accuracy but for sugar making experienced men can readily determine by observation when the correct density is reached for removing from the fire.

Syrup is not poured directly from the finishing vat to the marketing vessel but is placed to cool in a settling can. This is a heavy tin

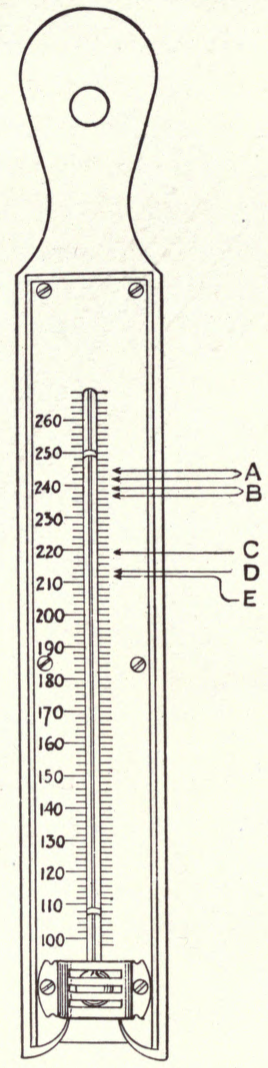

Fig. 28. THERMOMETER.

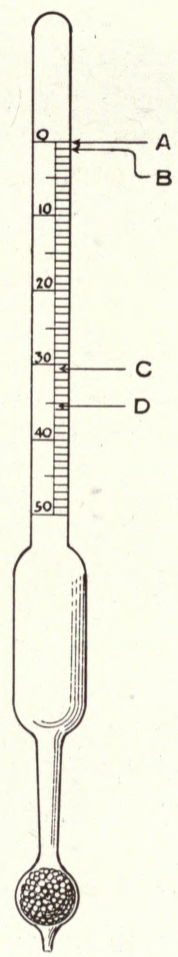

Fig. 29. SACCHAROMETER.

In Fig. $28 \mathrm{~A}$ indicates the boiling temperature for hard sugar; $\mathrm{B}$ for soft sugar; $\mathrm{C}$ for standard syrup; D for sap and $\mathrm{E}$ for water, all at sea level.

In Fig. $29 \mathrm{~A}$ indicates level when floating in water; B in sap; C in hot syrup and D in cold syrup-

vessel supported by iron hoops and holding about 25 gallons. It has a faucet placed three or four inches from the bottom to allow any remaining nitre to settle before the syrup is drawn off to be canned.

\section{SUgar.}

After the syrup has been properly settled the clear fluid is poured off through a felt filter or other strainer into a "sugaring off" pan and then placed on an arch or stove, and boiled until it reaches a gran- 
ulated state hard enough to cake into sugar. This granulated state can be ascertained by various methods. One is by the thermometer as already described. Another is by dropping a little of the boiling syrup into a cup of cold water, and if this forms itself into a hard lump at the bottom of the cup it is boiled sufficiently; but if it spreads over the bottom of the cup it requires more boiling. A third plan is to pour a little boiling syrup on packed snow or ice; if it hardens so as to crack under pressure it is boiled enough but should it run into the snow remaining soft more boiling is needed. After the operato ${ }^{*}$ is certain that the sugaring state has been reached the pan is removed from the fire and allowed to slowly cool until it begins to thicken when it is poured into small tins for caking. For soft or tub sugar less boiling is required. An imperial gallon of standard density weighs $13 \mathrm{lbs} .2 \mathrm{oz}$. and will make about nine pounds of sugar when cooled.

Because maple sugar is usually made into hard blocks it may not be generally known that it can be finished in a granulated or pulverized state. When the syrup is boiled to the temperature of 240 to 242 degrees, it will hardly make a medium hard sugar. When stirred sufficient to make the desired grain, it can be poured into the moulds, and by continuous stirring the sugar will granulate and form what is called "stirred" sugar. This sugar when dried out thoroughly may be pulverized which would make it almost as fine as flour and if of good quality almost as white. In doing this one has to observe great caution to prevent the sugar from scorching when drying.

In boiling syrup, more especially as it approaches the finishing point, the liquid has a great tendency to rise and froth in the pan and if not watched very carefully at times it flows over the sides. All sugar makers are familiar with this characteristic and with a means of combatting it. In the days of the old iron kettle it was a rule to suspend a piece of fat pork a few inches above the normal boiling level. When the rising syrup touched the fat it immediately subsided. Even yet this time honoured custom is followed and when the pork is clean no serious objection can be taken to it. Unfortunately, however, all makers are not particular about the quality of the oil or fat they use, as lard and frying fats are made use of in some camps. These, it need hardly be pointed out, tend to impart an undesirable flavor. In any case a very small quantity of an oily substance is sufficent to quiet the frothing mass and nothing will accomplish it more effectively than a bit of good butter or a few drops of sweet cream neither of which will impart an undesirable flavor. 
Cleaning the Pans.

At the conclusion of each day's boiling the evaporator pans should be removed from the arch and thoroughly cleansed, washing all scorched sugar, scum and nitre from the bottom of the syrup pan, and also sweeping from the bottom of the pan and between the corrugations all accumulations of soot. A convenient apparatus for removing the evaporator is a set of pulleys attached to an overhead truck running on a track crosswise of the arch. Through one of these pulleys a rope or chain is run, this is dropped down and hooked on to the sides of the evaporator pan. By arranging these for both ends of the pan it can be easily suspended and moved to the side of the building to be cleaned.

\section{Canning Maple Syrup.}

The question of canning maple syrup hot or cold has been discussed by many of the best sugar makers in Canada, with an opinion about equally divided as to the better method. Under these circumstances it has been deemed advisable to outline the two methods, and leave it with the producer to decide.

The fact that a gallon of hot syrup does not make a gallon when cold is in favour of cold canning. To illustrate, a gallon can filled with hot syrup, boiled at a temperature of $219 \mathrm{deg}$. will not weigh more than $12 \frac{1}{2}$ pounds, whereas the same can filled with cold syrup will weigh 13 pounds 2 ounces net. The objection to canning at high temperature is that after the can has been filled the syrup as it cools will shrink, and allow a vacuum to form above the syrup. This is objectionable because it may result in the quality of the syrup being impaired either by fermentation or crystallization and besides the purchaser may feel that he has been defrauded in not getting a full gallon of syrup. It is, therefore, safer to can syrup cold, or at a temperature not higher than $100 \mathrm{deg}$. Fahr. Canning in either of these forms should take place only after the syrup has been thoroughly strained and allowed to settle for some hours until transparent and quite free from a cloudy appearance.

Before filling the syrup cans should be thoroughly rinsed with boiling water, so as to remove the taint from rosin and acid used in soldering. Draw the syrup from the settling tank into the cansfor market, and allow ample time for all bubbles of air to break up and come to the surface, then pour in more and make sure that the can is actually full by tipping slightly so that the mouth is the highest point. Fill up with syrup to the top of the neck and screw on the cap lightly 
(only lightly). If square or oblong cans are used press against the side of the can with the hand so as to drive out all air, and when syrup is visible around this screw cap, sciew it down firmly with the pressure of the hand still on the can. The can is thus full from top to bottom, and the syrup if of proper density will keep indefinitely.

If round cans are used, instead of pressing the sides of the can with the hand to force out all air, as is practised with square or oblong cans, take hold of the handle and raise the can and fill the can to the top of the neck or screw cap, then screw on the cap perfectly tight while the can is still suspended by the handle.

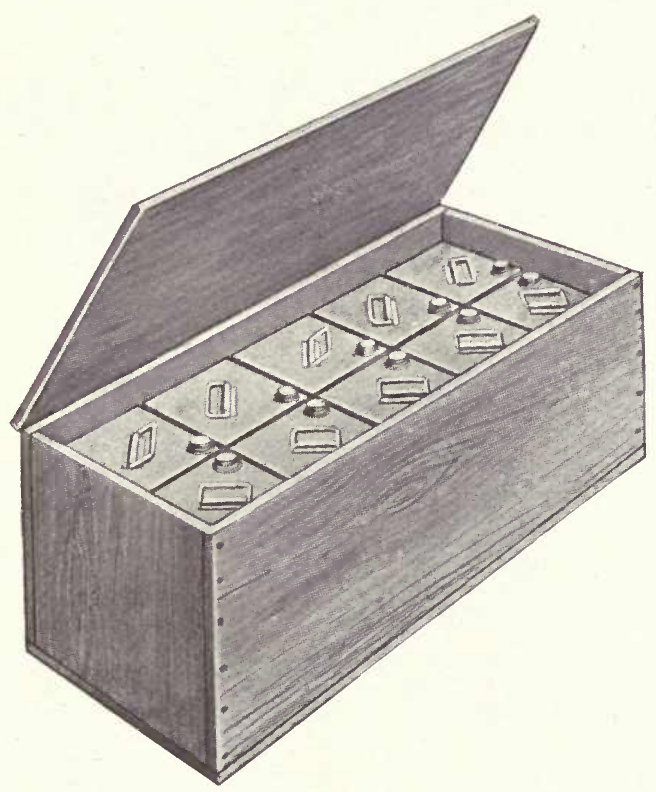

Fig. 30. A CASE OF MAPLE SYRUP READY FOR SHIPMENT

Syrup cans should be made from a good quality of tin. A square or oblong can is preferable, as being more easily packed, less liable to leak, has expansion to allow the syrup to change with the temperature of the weather, and when labelied has a better appearance. For shipment cans should be packed in boxes and in crates. It often happens that a package of syrup is left lying round, and the cans in crates get dirty which hinders their ready sale. When packed in a tight box they are kept clean and when exposed for sale present a good appearance. The size of the can depends on the market; gallon and half-gallon are probably the best sellers. 
A good label placed on the cases of syrup or packages of sugar, with the purity of the article distinctly declared on it, with the name and address of the packer or producer shown, should give confidence to the purchaser, and is an assurance to the latte. that what he is getting is genuine and above suspicion. The purchaser cannot be blamed if he is suspicious of goods that are put up without such labels.

\section{Storing Syrup and Sugar.}

If syrup is of proper consistency and is canned as directed in a foregoing paragraph it will keep from one season to another without deterioration. The storage temperature should be cool and fairly uniform but not near the freezing point as then it tends to crystallize.

Maple sugar does not keep well in a moist atmosphere. It tends to absorb water and molds readily more especially if it has been finished at too low a temperature. Maple sugar, therefore, to keep well in storage, should be boiled at a high temperature. After being taken from the molds it may be wrapped in parchment paper but should not be put in covered containers unless sealed air tight. In such containers it may be stored in a cold place that is dry but otherwise a dry, warm, even temperature is best.

\section{Putting Away Utensils.}

At the end of the season all utensils should be thoroughly washed and cleansed with hot water, and packed away carefully during the summer in an absolutely dry place. Owing to the dampness in houses built in heavily timbered groves it is often impossible to utilize the house for storage purposes; in that event they should be removed to some dry and tight building outside the bush. The buckets should be corded up one on top of the other, instead of nested, as packing closely together is injurious in a moist air or during wet weather. If for lack of space they cannot be corded, they should be nested only after being thoroughy dried by placing on the sides for an hour or two in the hot sun. 


\section{MARKETING}

Maple syrup and sugar can hardly be considered at the present day as products of general commerce as are white sugar, tea, flour, or the like, which enter into the regular household economy of the average family. Indeed it is safe to infer that thousands of Canadian families know nothing of these products although some of them may have bought for the first and last time a compound or a flavoured sugar bearing a name or design suggestive of the Canadian emblem. Genuine maple products of fine quality have entered the class of luxuries that are called for more and more as people become better off. Because maple sugar possesses a distinctively delicious flavor and is therefore in more or less demand, more particularly during the spring months, the candy maker has sought in various ways to produce from cheap sugars compounds to take its place. Such mixtures are usually composed of cane sugar and glucose to which has been added a greater or less quantity of strong flavoured, low grade maple sugar or, worse than that, an extract made from coal tar or other substances designed to impart a "maple" flavour. These substances unfortunately not only supplant the genuine maple goods but they do not for long satisfy the palate and when taken for the sugar they seek to imitate, tend to drive away a customer from the genuine goods. In this way imitation sugars are more injurious to the industry than maple sugar of poor quality which can always be sold to the confectioner at a price that appears to satisfy the indifferent maker. Indeed it is a remarkable fact that even the better class of grocery stores are able to handle considerable quantities of very indifferent sugar. So long as it is genuine, people will use more or less of it as an annual treat. All purchasers are not satisfied with a dark, strong sugar, but want a better grade which can always be depended on to bring a higher price. Occasionally the very best grocery stores display really first-class maple products to supply discriminating customers who are willing to pay the extra price which is always demanded for them.

It is not through the regular commercial channels that the first grades of maple sugar command the highest prices. The private customer is the best outlet for the superior article of which the wide-awake maker seldom has enough to go round.

After one has taken the pains to make a first-class product, it is worth his while to seek out the best paying customers. A thousandtree maker in Compton County, Quebec, who covers his buckets and takes every other reasonable precaution to make fine goods, sells 
practically every pound he makes in local towns and the City of Sherbrooke. At first a little peddling was necessary but the quality of his goods and generous measure acquired a reputation that spread to an ever widening circle. This grower never takes less than $\$ 1.25$ per gallon for his syrup or $12 \frac{1}{2} \mathrm{c}$. per pound for sugar which is moulded in hard 5 to $10 \mathrm{lb}$. cakes. Another maker puts his fine sugar up in 2 oz. cakes for which he gets 20c. per lb. from all old customers and new ones reached by samples. In another case an extensive maker is said to dispose of the bulk of his crop to private customers at 30c. per $\mathrm{lb}$. for the sugar and $\$ 2.00$ a gallon for syrup.

\section{Developing a Market.}

At a meeting of the Vermont Sugar-makers' Association a New York State sugar-maker related his methods and experiences in selling maple products. After canvassing New York and Philadelphia with indifferent results he commenced a system of circularizing distant localities until he now sells the great bulk of his crop in Western States markets. His story is interesting and is given in abridged form.

"After the last trip I made to the city of Philadelphia I returned home and got out a little circular. I had photographs made of the groves and then I compiled a little book about the making of maple syrup on "Scotch Mountain Groves" (that is what we call our sugar orchard) for the purpose of advertising. I also had taken various photographs of the evaporator house, the camp where we live and board the men during the season, the teams, the interior of the evaporator houses, etc., and then I wrote a little thesis describing the groves, the equipment, the methods used in the production of our maple product, particularly the care and cleanliness used. All this time I had been collecting names of people who might be interested in this class of goods. I then went to the editors of our local papers and asked to look at their subscription lists. They were glad to show them and from them I made a list of the people who had gone west for I. knew they could not procure it in the west. Then I wrote my many friends and some of my customers throughout the west and asked them to send me names of people and proprietors of grocery stores who might be interested in my product. It was but a short time before I had quite a list. Then to each name on that list went this little pamphlet. This has been repeated every year; as I get a new name I add it to my list and send this pamphlet.

"I don't get returns right away and I presume hundreds of the booklets go into the waste baskets. There is no question about 
that, because I have sent out probably from 2,500 to 3,000 copies but I don't stop at that; if they don't write me for goods I don't let them alone. In the spring and fall I come at them again; I get out circular letters telling them something more about the product and I mail these. I don't seal them and so my postage isn't large; although in the beginning it is quite an expense but the expense lessens continuously. I change my circular letters making them somewhat flowery. The people in the west don't know the season of maple syrup and don't know when they want syrup until they see something that will remind them of it and you would be surprised to see how the orders come in after this circular letter has gone out in the spring and fall.

"One season I got an artist to make a maple leaf. I had it put on a postcard. It cost me five or six dollars for say 500 of them. It had on it the name of the groves and the compliments of the season just as if it was Christmas time. It was maple sugar time or maple syrup time and we wanted to remind our friends of it. Another season I took a picture showing some trees in my grove with covered buckets, and sent that out.

"My price is $\$ 1.25$ per gallon. Perhaps I made a mistake in not starting my price higher but I never take less than $\$ 1.00$ per gallon and my product is not going into the commission market where jobbers cut the price so I get nothing for it. The last runs, the dark syrup, I sell at $\$ 1.00$ a gallon and there seems to be no complaint whatever, and I find that it pays better than to ship my surplus product and have returns come back so small I can hardly see them. I have spent a great deal of time and work in establishing a market but the work lessens as time goes on. Orders are coming in more easily and I am shipping from early in the fall until the season opens up again. For the past few years my product has been entirely taken care of in this way."

\section{Profits From Sugar Making.}

A prize winner in the syrup contest, referred to on later pages, who taps three thousand trees, kept an accurate account of his transactions for the season of 1913 .

The sugar bush, which is on rocky land of little value for agriculture, is situated two hundred miles from his home. The bush is on sloping ground which enables the owner to gather the sap by gravitation. For this purpose he has laid a system of galvanized iron pipes connected with twenty-two reservoirs distributed throughout the bush for receiving the sap which flows directly to the receiving vat at the sugar house. 
The Expenses for the season were as follows:-

Railway fares.................. \$17.10

Groceries and provisions............. 30.85

Wages of men and cook............ 83.10

Hotel and minor expenses............ 5.75

Cartage........................ 24.75

Fuel... . . . . . . . . . . . . . . . . . . . . 44.00

Freight and express.............. 10.00

Cans and crates................ 53.00

Total....................... $\$ 268.55$

The returns were as follows:-

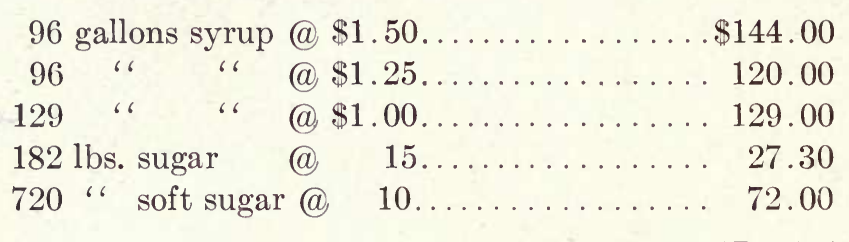

Total.................... $\$ \$ 492.30$

Practically five weeks were occupied from the preparation for tapping until the camp was closed.

This sugar maker estimated that if he had done the work at home he could have saved the railway fares, half the cost of preparing fuel, half the cartage expenses, all the hotel expenses and twenty dollars of wages which would have left a net return of $\$ 322.87$ for his five weeks work and depreciation of and interest on the value of the sugar plant which cost $\$ 1100$.

It must not be overlooked that most of this maker's products were of very good quality and sold for such prices as they were worth.

The season of 1913 was in no sense a big sugar year as this bush yielded only at the rate of 145 lbs. of sugar per tree whereas it has yielded as high as $2 \frac{1}{2}$ lbs. per tree. 


\section{BY PRODUCTS OF SUGAR MAKING}

In the process of making maple sugar and syrup two by-products are obtained from which a considerable revenue might be secured. These are maple vinegar and sugar sand.

\section{VINEGAR.}

It is estimated by an experienced sugar maker that from the product of 1,000 tapped trees one may easily make from 25 to 30 gallons of very fine vinegar from materials that are usually thrown away. To this may be added in some seasons a considerable quantity of late "buddy" sap that will not make good sugar. While making is in progress one should have at hand a barrel into which is poured the washings and drainings of all sugar utensils, including the strainers, pans, etc. By the end of the season the quantity thus saved will amount to a good many gallons.

If kept moderately cool (about 50 deg. F.) alcoholic fermentation, the first essential stage in the making of vinegar, will probably take place spontaneously in the barrel. It is better, however, to make the fermentation sure by putting in a little yeast. A cake or two of compressed yeast will serve the purpose well, or table raisins may be used.

When the alcoholic fermentation (which will usually require about two weeks) is completed, the contents of the barrel should be carefully strained into a vinegar barrel. A small quantity of good "mother of vinegar", or some old vinegar, or both, should then be added and the barrel should be set on its side in a warm room about 70 deg. F.

The " mother of vinegar" is the slimy skin which forms on the surface of the vinegar. It consists of a mass of the bacteria which convert alcohol into acetic acid, the characteristic acid of vinegar.

The vinegar added to the barrel may best amount to about onetenth the volume of the alcoholic liquid. Care should be taken to free this vinegar from vinegar eels and vinegar flies. This can be done by straining through bolting cloth, flannel, or felt.

Two conditions favoring the production of vinegar are warmth and a free supply of air. To secure good results the half-full barrel should be laid on its side in a warm room and have bung holes opened at both ends so as to allow a free draught of air above the liquid. To exclude the vinegar fly the bung holes must be protected with either muslin or cotton-wool, which must be kept dry, or with a fine varnished metal screen. 
Sap to be made into vinegar should be boiled down to about oneseventh its bulk and then treated as already described for the washings of sugar plant utensils.

Where vinegar is made on a large scale, for instance by dealers in maple products, the process can be hastened by allowing the alcoholic liquid to drip slowly through a barrel of clean beech shavings which have been impregnated with warm vinegar to inoculate them with the acetic acid bacteria.

In flavor maple vinegar is far superior to most of the commercial varieties and it is regrettable that it is not more generally used. Much of the vinegar on sale in Canada as "white wine vinegar" is made in distilleries from pure alcohol and should properly be called "spirit vinegar." This, while perfectly wholesome, is of poor flavor as compared with maple vinegar, cider vinegar or malt vinegar.

\section{SUgar SAND.}

Sugar sand, known also as "nitre," is a product of considerable worth. Dr. J. F. Snell, Professor of Chemistry, at Macdonald Agricultural College, when addressing the Pure Maple Sugar and Syrup Co-operative Agricultural Association, in January 1913, referred to sugar sand as follows:-

"As the boiling of maple sap is continued and the sap approaches the consistency of syrup, a sediment of 'sugar sand' deposits. The main constituent of this sediment is malate of lime and from this two products of value are obtainable by a process discovered by Prof. W. H. Warren of Wheaton College, Norton, Mass., and afterwards independently by a graduate student working under my direction. One of these products is calcium bi-malate (bi-malate of lime) which is from the physiological standpoint the best acid constituent for baking powders yet discovered. Prof. Warren has used it to make baking powder and found it entirely satisfactory. It is doubtful whether, and in my opinion hardly probable, that it can be made either in sufficient quantity or at a low enough price to compete with cream of tartar-much less with alum and acid phosphate of lime, which are the acid constituents of perhaps three-fourths of the baking powder used in Canada to-day. It is, however, not impossible that calcium bi-malate may find a place as an ingredient of baking powders for the better class of trade.

"The second valuable product of sugar sand is malic acid itself. This substance now sells at ten dollars a pound. If there were to be put into my hands all the malic acid producible from the maple sugar 
sand of a single season in Canada and the United States, and I could dispose of it at the present market price, I should be a millionaire."

Sugar sand gathers in the felt and flannel strainers through which the hot syrup is filtered and what escapes these strainers settles as a sediment below the faucet of the settling syrup cans. An extensive sugar maker estimates that a thousand tree grove should yield from 40 to 50 pounds of sugar sand in a season. The yield varies greatly from year to year.

In preparing sugar sand for market it has to be thoroughly washed and rinsed with hot water, or hot sap, in order to take out the sugar. It must then be spread out to dry. The washing can be carried out in the felt strainer. The wash water may be boiled down to syrup or used for vinegar making.

It is understood that a German manufacturer has become interested in Canadian sugar sand as a source of malic acid and it is expected that this product well washed and dried will find a market at a price not below ten cents per pound. 


\section{A CO-OPERATIVE MAPLE SUGAR MAKERS' ASSOCIATION}

There has been organized with headquarters at Waterloo in Shefford County, Quebec, a co-operative sugar makers' association. It is named The Pure Maple Sugar and Syrup Co-operative Agricultural Association and promises to greatly help the industry by assisting those engaged in it.

This association was organized in January 1913 and already has a membership of several hundred distributed in Ontario, Quebec, New Brunswick and Nova Scotia.

The following extracts from the by-laws, constitution, and resolutions of the association were supplied by the Secretary.

The head office is Waterloo, Que., until changed by the board of directors, but the meetings are held in different parts of the Country as decided upon at the preceding meeting.

The object is the advancement of the maple sugar industry generally by holding meetings for the discussion of all questions relating to said industry, by collecting, arranging and disseminating useful information and by such other means as may from time to time be deemed advisable.

The officers are Patrons, Hon. President, a President, Vice-President, five Directors, Associate Directors and a Secretary-Treasurer.

Any person may become a member by paying an annual fee of one dollar.

The directors have so far worked for the following objects:

1st. To get the law changed to stop the sale of compound syrups in the place of the maple syrups by deceitful names and devices.

2nd. By trying to induce our Governments to assist us in instructing the agricultural classes in the way of improving the quality of their output of maple products by lectures and experimental stations to teach the young.

3rd. By soliciting the Governments to assist us in having yearly exhibitions of maple products to stimulate the producers to better their output and to show the consumers the difference in the different productions.

4th. By helping the members to get a market for their products.

Present Officers are: Patrons, Hon. Martin Burrell, Minister of Agriculture, Ottawa, Hon. J. E. Caron, Minister of Agriculture, Quebec; Hon. Pres., Prof. J. F. Snell, Chemist, Macdonald College. President, M. F. Goddard, Waterloo; Vice-President, Chas. F. Fisk, 
Abbotsford, Directors, J. H. Grimm, Montreal; R. T. Brownlee, Hemmingford; J. A. Dupuis, DesAulnais; Secretary-Treasurer, Jos. H. Lefebvre, Waterloo, Qu?.

\section{Co-Operative Marketing.}

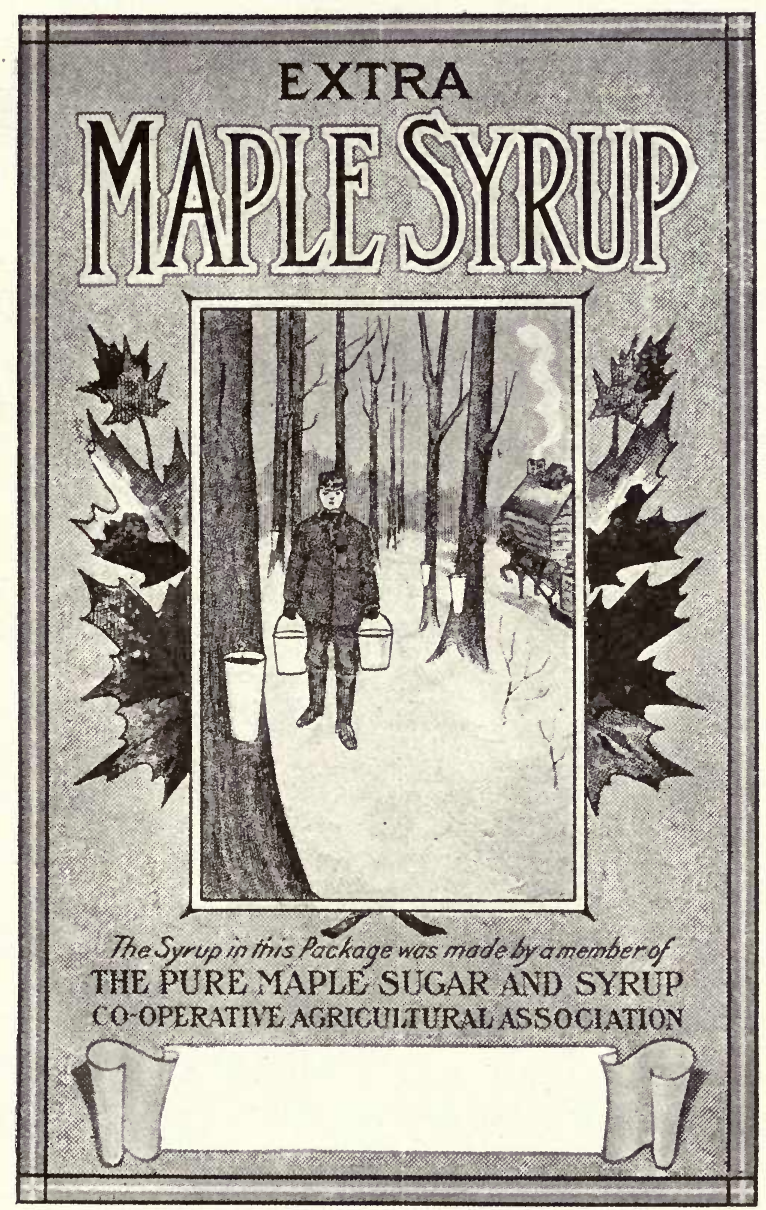

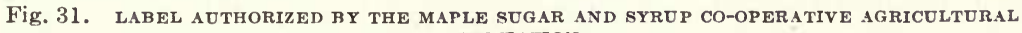
ASSOCIATION

The white space at the bottom is for the name of the member using the label

Although it was late in the winter of 1913 when organization was completed a beginning was made in marketing sugar and syrup cooperatively. Some five thousand gallons of syrup and a considerable 
quantity of sugar of the crop of 1913 were marketed. The goods were handled at comparatively little expense and very satisfactory prices were obtained. A great expansion in this branch of their work is looked for as the membership increases. The association uses a label shown on paga 53, which is calculated to be a guarantee of genuineness. Members can obtain a supply of these from the secretary.

From the experience of the first season the officers of the association are encouraged to believe that if entrusted by the members to do so they will be able to handle their whole output. The sugar and syrup will be graded and sold to the best possible advantage. This plan would secure the benefits of co-operation and thus do away in some measure at least with competition which in many cases reduces the price. Selling goods according to grade will have the further good influence of educating the public on quality and in encouraging makers to improve their method of manufacture.

Maple sugar makers wherever in Canada they may be situated will do well to associate themselves with this co-operative movement which should do much to build up and greatly improve an industry that has for a number of years shown indisputable signs of decline.

\section{The Benefits of Organization.}

At the meeting at which the Pure Maple Sugar and Syrup CoOperative Agricultural Association was organized Mr. A. A. Carleton, President of the Vermont Maple Sugar Association, delivered an address on the benefits of organization. The Vermont Association has been in operation for twenty years and has therefore valuable lessons for Canadian sugar makers. Following is Mr. Carleton's address in abridged form:-

The benefits of an association, when backed by the Government, and good Legislation are numerous and a great help, to the producer as well as the consumer. "In union is strength," therefore by uniting our minds, wills and personal push in an association we are bound to further the cause for which it is formed. I consider the circumstances which beset you farmers are similar to those which we people of Vermont have had to contend with. As the demand for our maple products has increased, the "mixers" have also increased their output, although the amount of pure maple goods remained the same.

By strenuous efforts on the part of the sugar makers, as an organized association and backed by the Government of Vermont, we have now a "pure food and drug law" which strictly prohibits the adulteration and misbranding of food products, including maple sugar and syrup. 
The association issues a protected label to its members free, upon their agreement, filed with the Secretary, that they will use it only upon packages containing pure maple sugar and syrup of standard quality and of their own manufacture. Any improper or unauthorized use of this label or any adulteration of the products covered by the same, will be prosecuted by the association to the full extent of the law. The penalty is not less than $\$ 50$ or more than $\$ 200$ for each offence. One half of the fine goes to the complainant.

Has the passage of this Act, aided the Vermont farmer and the maple sugar industry or will like legislation better the prospects of the farmer and the maple industry of Canada? I will answer both questions alike. Yes. If something had not been done to prevent the decrease in our maple product, in a few years it would probably have passed out of existence.

I know you, as well as we of Vermont, have had discouraging circumstances to deal with. Why has not the production of pure maple sugar increased with the demand? First the increase has been met by the mixer; the farmer is discouraged, he can not make the pure maple sugar of No. 1 quality and compete with the spurious article of the mixer at the price the latter is placed on the market, when labeled as pure maple sugar, when in reality but a small per cent, if any of it, ever c..me from a maple tree. The securing of labor has been a severe problem with us in Vermont, but the most lamentable and inexcusable part of the whole industry is the production of a poor grade of sugar which is fit only for the mixer, tobacco factories and the distillers of liquor. The prices paid were so low that the farmer received poor remuneration for his labor, causing him to stop making and in many cases being short.of ready money, he has cut down the old sugar place which was the pride of generations. The timber has been sold to the ever greedy mill but a wrong has been committed which succeeding generations cannot repair.

When we consider the fact that the little State of Vermont, with only 10,200 square miles, has a yearly income of $\$ 1,086,933$ from her maple products, we realize the industry is worth fighting for. I seem to see two classes of maple sugar makers, one class laboring as of old, with the same old notions, and following the same old methods, while the others comprehend that they are manufacturing an article which is used as a luxury and not as a commercial commodity. This latter class use their best endeavors to perfect their goods. The former are working under difficulties, while the latter are getting abundant returns for their labor. 
We as American maple sugar makers must control our sugar product and place it in the hands of the consumer. First it pays better to do so and second it insures purity. We know how the pounds multiply as they pass through other hands in our large cities. It is a duty we owe ourselves, our nation and our customers that we provide some means whereby sugar may reach its ultimate destination in the pure state it leaves the camp and that the consumer and producer may be protected and thereby share in the profits of the speculator and the middle-man. In Vermont more new up to date sugar making apparatus and equipments have been installed in the past five years than ever before in the history of the industry. What has made the change? The "pure food law" faithfully enforced and the work of our association. Our state appropriates $\$ 500$ yearly for the Maple Sugar Makers' Association, to use in increasing, promoting, and advertising the maple sugar industry in the state and so assisting the farmer to increase his income. Never before in the history of Vermont were the prospects of the sugar mak $ə r$ brighter than to-day. People are alive to the fact that quality counts and are willing to pay 25 cents per pound for No. 1 and from $\$ 1.50$ to $\$ 2.00$ per gallon for prime syrup. As the purchasing public become alive to the quality of fine, pure goods and as makers learn to manipulate their plants so as to turn out choice products there will be less and less of the strong, black kind made that will bring only 8 cents per pound or 75 cents per gallon.

The wealth of the world is for those who can get it, let us get ours in a legitimate way by drawing from the people of wealth our share of their income, which they gladly spend to secure luxuries of quality and purity. 


\section{A MAPLE SUGAR CONTEST}

Primarily with the object of encouraging improvement in the methods of making maple syrup and sugar, and secondarily for the purpose of securing samples of No. 1 quality to be used in educating the public, Mr. John H. Grimm of Montreal, a director of the Pure Maple Sugar and Syrup Co-operative Agricultural Association, conducted in the spring of 1913, a maple syrup and sugar contest in which were awarded prizes amounting to five hundred dollars. In the syrup section there were 513 contestants and in the sugar section 233 . The entries, which came from each of the four sugar making provinces, were judged by Prof. C. H. Jones of the Vermont Agricultural College who is considered perhaps the most capable judge of maple products in the world. In judging the maximum points al.owed were for syrup, flavour 60 , colour 25 and body 15 . In judging sugar 60 points were allowed for flavour and 40 points for colour.

The following tables give the winners, the scores and the prizes won in the syrup and sugar sections.

THE SYRUP SECTION

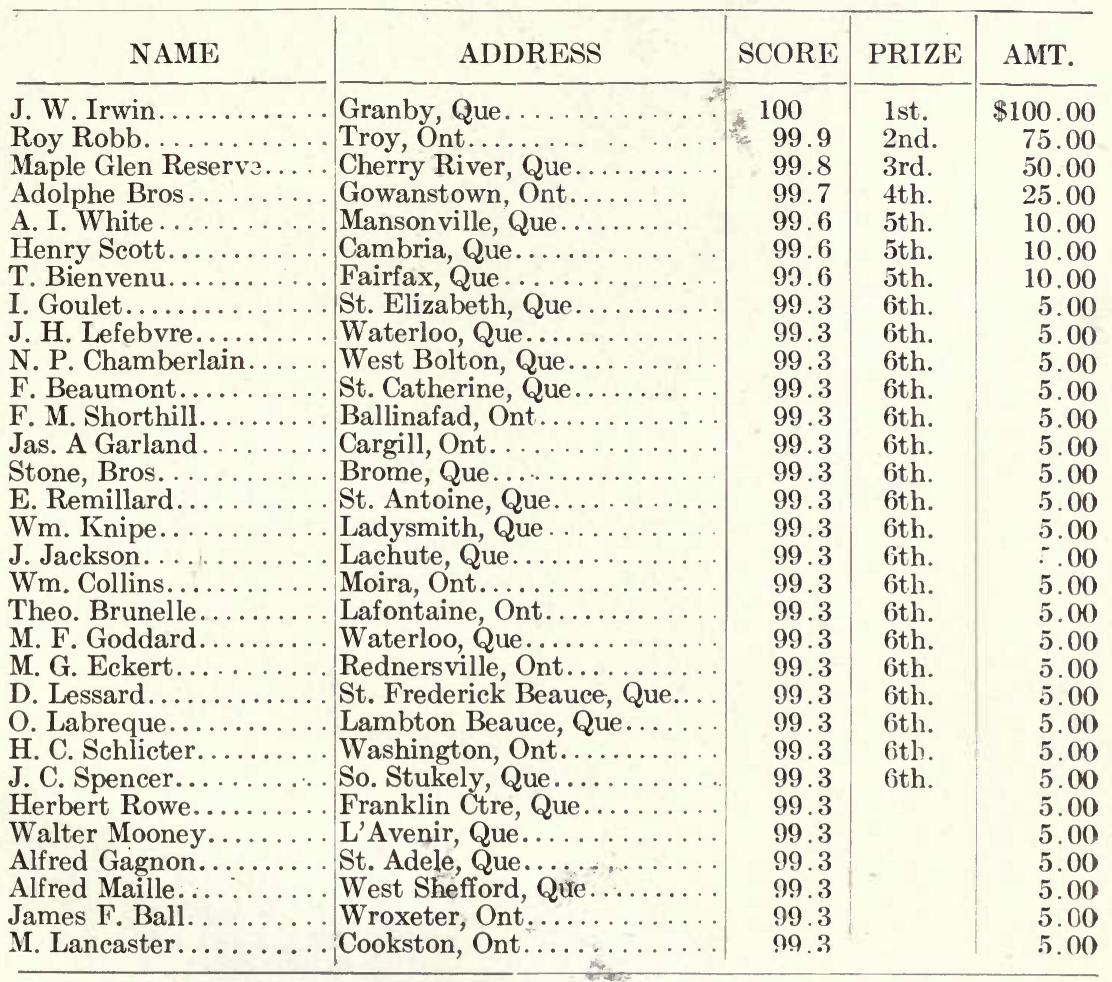




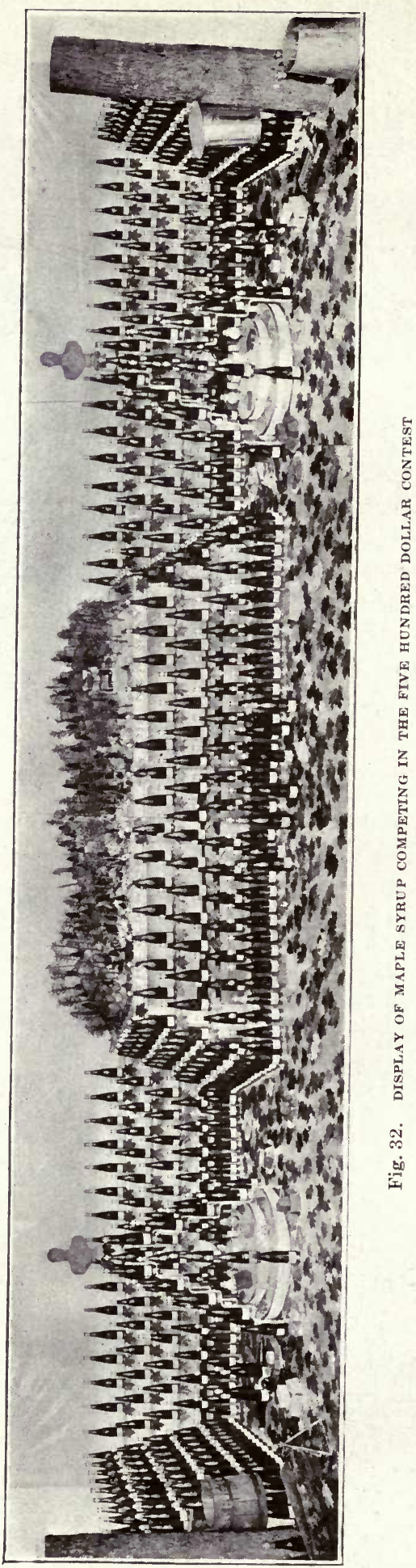


THE SUGAR SECTION.

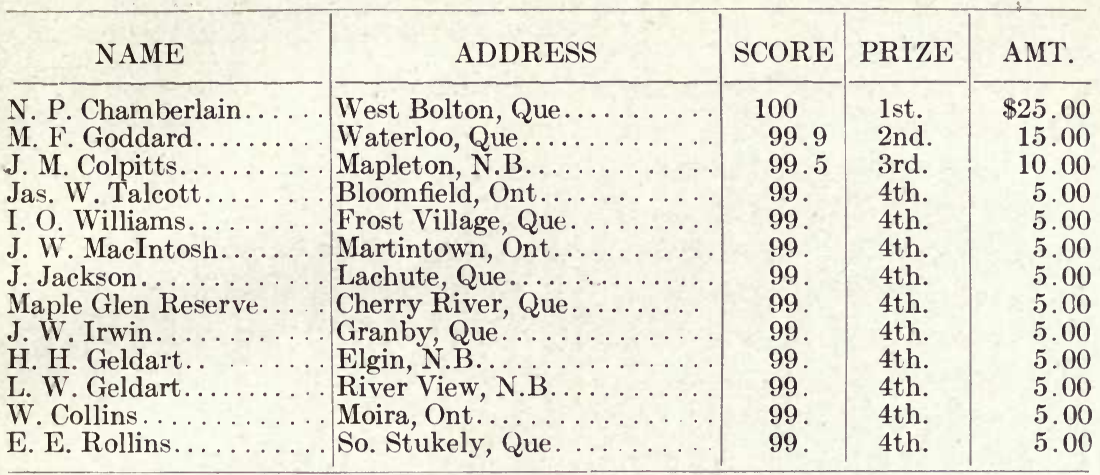

In this contest a number of important points are brought out. Contrary to the opinion that soft maple is not good for sugar making it is shown that good syrup may be made from the sap of this variety. The grove from which the first prize syrup and one of the fourth prize sugars was made consisted of one-third soft and two thirds hard maple trees.

The contestants in almost every case operated large sugar plants. Two hundred of the reports, selected at random, showed the average sugar grove to consist of about 24 acres and contain about 1,800 maple trees, fifty per cent of which were tapped.

About fifty-seven per cent of the groves were on rocky land unfitted for cultivation, and about 25 per cent practicably untillable. The character of the soil varied from rocky to clay and included clay loam and gravelly conditions.

According to the judge the syrups winning the first four prizes, and which were made in some cases hundreds of miles apart were so nearly alike in colour and flavour as to give one the impression that they were all made by the same maker from the same grove. From the high scores made by the remaining 27 prize winners it is evident that the entries were of very high quality. Practically the same remark appli is to the sugars. On page 4 are shown correct representations in colour of the prize-winning syrup and sugar all of which graded No. 1.

\section{How the Prize Winning Goods Were Made.}

In order to learn for the benefit of the readers of this bulletin how the prize winning syrup and sugar were made a set of questions was sent to each successful contestant. From the replies received the following points are deducted:- 
Spouts and vessels: All the prize winners use galvanized, steel spouts of tapering form so as to be held by the bark, instead of being jammed against the sap wood, and to be easily withdrawn. The spout is so constructed as to exclude air from the bore. Most of the hauling and storage tanks are of galvanized iron. A number of makers expressed a preference for tinned tanks. The buckets used are chiefly of tin many of them painted on the outside.

Covers: The majority of the prize winners use covers on their sap buckets and most of those who do not express their intention of getting them before next season. Some say that covers will pay for themselves in one season if at all stormy as they keep out the rain and snow and washing from the trees, and save fuel and time of boiling and insure a lighter, better flavoured syrup.

Cleaning and care of sap utensils: Without an exception the pails and tanks are well washed and by many scalded at the close of the sugar season, thoroughly dried in the sunshine and stored upside down in dry airy quarters. These, as well as the spouts, are again thoroughly washed at the beginning of the season and the tanks are washed two or three times during the sugar season or as often as they appear to need it. Some makers make it a rule to wash out the tanks at the end of each run of sap.

A prize winner who greased the inside of his sap buckets with tallow at the close of the previous season to prevent rusting had to throw away the first run of sap because it was tainted by the grease.

The evaporator: All makers use a modern evaporator having a corrugated bottom. Most of them clean the inside and brush the bottom free of soot after each boiling. In some cases where covers are used and the sap is carefully strained makers find washing once in two or three days sufficient. All agree that the pan needs washing whenever it appears dirty on the sides. Some makers wash with hot sap using a brush and cotton cloth. The use of sour milk followed by clean washing is recommended for removing nitre from the pan. One prize winner changed the position of the two back pans of the evaporator every morning while another changed them at noon also.

Boiling the sap: All agree that sap deteriorates quickly, therefore, the sooner it is made up the better. Even in times of a slow run some of the successful makers gather and boil each day while a few others consider that boiling once in two days may do in very cool weather, more especially if ice is used to keep the sap cold. For rapid boiling all recommend shallow boiling and the use of very dry, sound wood finely cut. At least part of the wood should be soft as it is more inflammable. 
Finishing the Syrup: In almost every case the prize winning syrup was finished in the main evaporator. Reheating is claimed to darken the syrup. One maker drains off the syrup every five minutes at a temperature of 219 degrees.

Straining: Every maker who reported strains the sap once and the syrup once. Several of them strain the sap twice, once through a fine wire strainer in the gathering tank and once through a cotton strainer into the storage tank. Several strain the boiling syrup through felt strainers specially made for the purpose while others use two or three plies of heavy flannel or blanketing.

Sugar: The prize winners agree that to make really fine sugar it is necessary to have choice, light coloured syrup. This should after being strained through felt or flannel be boiled rapidly in not too large batches in a sugaring-off pan. If the sugar is for long keeping it is better to be finished with very little stirring and be put into the moulds hot. It then turns out hard and granular and will not leak. If, however, a less flinty sugar is wanted for early consumption it is better to stir it almost constantly while cooling. This will give a softer sugar that is easily cut with a knife. Some of the prize winning sugar was of the semi-transparent, flinty kind while others were of the more mellow consistency but all were light in colour corresponding closely with grade No. 1 represented in Fig. 3 shown on page 4 .

Packages: Makers who do a retail trade in syrup recommend halfgallon and gallon cans bearing an attractive label.

Additional Considerations: Cleanliness and speed are given as the chief considerations in making a high class product. That is to say all vessels must be kept as clean as possible and the sap must be gathered frequently, strained thoroughly and boiled rapidly until finished. Continuous boiling or re-boiling darkens the syrup.

It was pointed out by several makers that the public require to be educated to recognize a first-class product of syrup and sugar. As consumers learn this they readily demand the better goods for which they willing'y pay a price corresponding to their value. 


\section{THE FUTURE OF THE INDUSTRY}

The maple sugar industry has, during recent years, shown an unmistakable inclination to decline. As already pointed out on an earlier page, the yearly production of sugar, together with its equivalent in syrup, fell from more than $22,000,000 \mathrm{lbs}$. in the eighties of the past century, to about 20,000,000 lbs. during recent seasons. This is not to be wondered at, because, until quite recently, no organized effort had been made to keep it alive.

As the population and wealth of the country have increased, and with these the demand for luxuries, there should have been an ever increasing market for maple products. Certain manufacturing firms have recognized this, and in order to reap the advantage of the name "maple" have resorted to the making of compounds composed chiefly of cheaper sugars and glucose to which is added a greater or less proportion of strong flavored maple sugar, and in some cases, flavoring extracts. It is firmly believed by makers of genuine maple sugar, that these compounds not only undersell and displace pure goods, but, in many cases, deceive the purchaser. The newly formed Pure Maple Sugar and Syrup Co-operative Farmers' Associations will exert their influence in the direction of protecting pure maple products against the evils of adulteration.

It is not to be overlooked, however, that perhaps sugar makers themselves are to blame for making room for the "mixer," as the compounder of sugars is called. Unfortunately, too little maple sugar and syrup are of good quality. This may partially account for the decline of the industry because so much of the goods have to be sold at a low price.

\section{Grades of Maple Products.}

In order to ascertain, for the information of readers of this bulletin, how Canadian maple sugar and syrup grade, well informed authorities who handle the great bulk of these goods in Canada, were consulted: As a result the astonishing information was obtained, that not more than ten per cent of Canadian maple goods grade No. 1, while fifteen per cent grades No. 2, fifteen per cent No. 3, and sixty per cent No. 4. That is to say, of the $20,000,000 \mathrm{lbs}$. made each year fully $12,000,000$ lbs. are of No. 4 grade, having a market value per lb. of about one-half that of No. 1 goods.

Of this $12,000,000 \mathrm{lbs}$. practically none is marketable by the makers to private customers, while the much larger proportion of the $2,000,000$ lbs. of No. 1 grade, and more or less of the No. 2 and 3 grades, are sold 
direct to consumers. The market price to the grower of these several grades, when sold to good advantage, are said by authorities to be for syrup per gallon $\$ 1.50$ for No. $1, \$ 1.25$ for No. $2, \$ 1.00$ for No. 3 , and 70 cents for No. 4, and for sugar per lb., 15 cents for No. 1, $12 \frac{1}{2}$ cents for No. 2, 10 cents for No. 3, and 7 cents for No. 4. These are average prices, and are much exceeded by some makers of goods of first quality.

According to these valuations, only a small proportion of Canadian sugar makers secure more than a very low price for their products. The $12,000,000$ lbs. that now bring only $\$ 840,000$ would be worth $\$ 1,200,000$ if raised to No. $3, \$ 1,500,000$ if No. 2 , and $\$ 1,800,000$ if of first quality. Nor need there be fear of a reduced price if the production of the better grades were increased, as even the highest prices given are still below those of fine candy, which is no more delicious than prime maple sugar, which even now brings a fancy price when tastily put up.

As pointed out by one of the successful competitors in the syrup competition, there is much to be done in educating the consumers in regard to quality of maple products. This will have to be accomplished partly through the eye, and partly by way of the palate. To show the appearance of the different grades there are printed on page 4, Figs. 3 and 4 in natural colors, representing sugar and syrup of grades Nos. 1, 2, 3 and 4. The samples from which these illustrations were made were selected by an expert of wide experience.

\section{Maple Sugar a Luxury.}

If all makers of maple products would fully realize that their sugar and syrup are articles of luxury, and make and put them up accordingly, there would undoubtedly grow up a tremendous demand for them, not only in Canada but in other countries. Great Britain is ready to take a liberal supply of choice goods. For this purpose a syndicate, composed chiefly of Canadians, has been formed in London to handle Canadian sugar and syrup and eventually to introduce the pure product into the British market. If pure goods of prime quality can be obtainable this body is said to be prepared to handle several thousand tons a year. But an inferior article, such is at present procurable, would have no chance of success with the better class of consumer to whose taste it is intended to make an appeal. The day of the coarse, dark, unattractive blocks of sugar is over and the maker should now discern the fact that its production does not pay.

The preservation and development of the maple sugar industry means more to Canada than the annual production of a quantity of table sweets. It means the conservation and improvement of hundreds 
of thousands 0 acres of grove and forest trees of a variety of which every Canadian is proud. To vastly too great an extent the majestic maple has been cut away for the fire place and the factory until, in many districts, once clothed with maple forest, there remains only a small number of roadside trees bearing the Canadian emblem. It could not be expected that the forest could be preserved on prime farming land, but there would seem to be little excuse for denuding great stretches of maple-ctothed rocky soil, that when cleared is deprived of usefulness. A maple grove or forest is for its lumber and fuel, an asset rapidly increasing in value and when to these products there is added an annual crop of sugar of such fine quality as to constitute a luxury, it may fittingly be designated an orchard. When a maple grove merits, as that of no other forest tree can, the designation " orchard", it will have reached a plane on which it may rest with comparative safety. It would seem to be a duty, that might be regarded as a privilege, on the part of legislators, farmers, and all other classes of the community to do what they can to protect and otherwise encourage the maple sugar industry.

The future of the sugar maker seems bright with hope if he will but attach to his work that dignity which rightly belongs to it. Pure and fine products of the maple tree hold an enviable position among luxuries in the homes of well-to-do people, and will continue to increase in value. To secure the benefit of this advance the grower requires not only tc. furnish his plant with modern equipment, but he must exercise the utmost care, as does the maker of choice butter, in every stage of the process of manufacture. In doing this let him remember that he is one of a body of more than fifty thousand Canadian sugar makers that are aiming at the same goal-the saving of a threatened industry, and he will accomplish much, not only for himself, but for succeeding generations. In this, as in all great enterprises, there is strength in union. The newly formed Pure Maple Sugar and Syrup Co-operative Farmers' Association has an important work before it. Its interests are those of every farmer who taps a tree. Let him recognize this and give the organization his sympathy and support. 





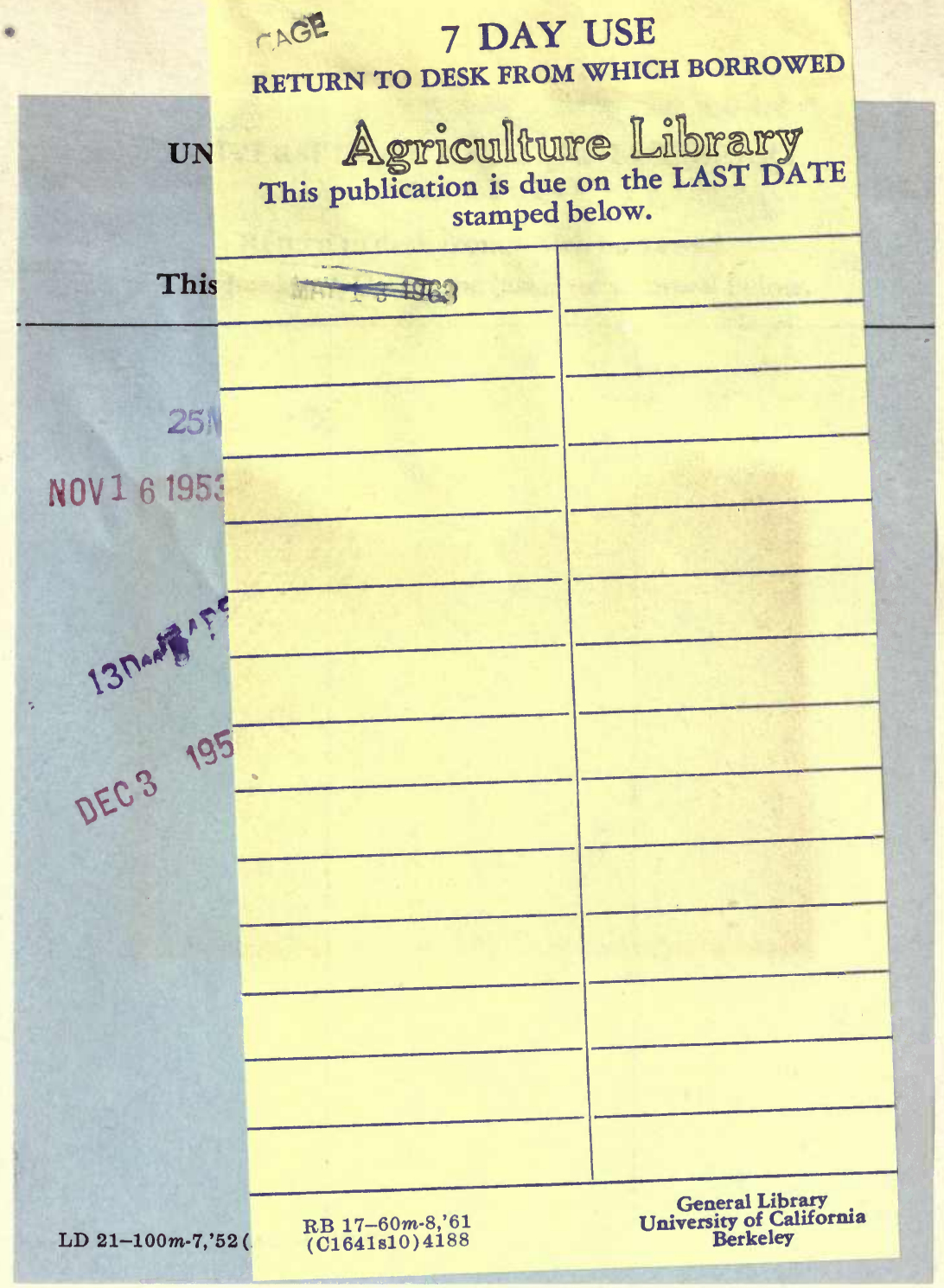




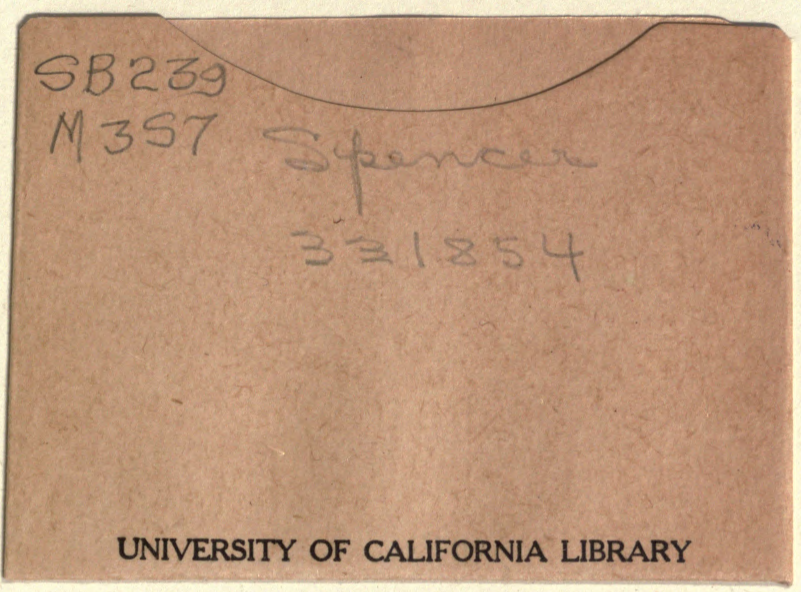


